\title{
Stimulus-specific adaptation in the inferior colliculus: The role of excitatory, inhibitory and modulatory inputs
}

\author{
Yaneri A. Ayala ${ }^{\mathrm{a}, \dagger}$, David Pérez-González ${ }^{\mathrm{a}, \dagger}$, Manuel S. Malmierca ${ }^{\mathrm{a}, \mathrm{b}, *}$ \\ a Auditory Neurophysiology, Institute of Neuroscience of Castilla y León, University of Salamanca, 37007 Salamanca, Spain \\ ${ }^{\mathrm{b}}$ Department of Cell Biology and Pathology, Faculty of Medicine, University of Salamanca, 37007 Salamanca, Spain
}

\section{A R T I C L E I N F O}

\section{Article history:}

Received 30 April 2015

Received in revised form 27 June 2015

Accepted 30 June 2015

Available online 6 July 2015

\section{Keywords:}

MMN

SSA

GABA

Glutamate

Acetylcholine

Auditory

\begin{abstract}
A B S T R A C T
Patients suffering from pathologies such as schizophrenia, depression or dementia exhibit cognitive impairments, some of which can be reflected in event-related potential (ERP) measurements as the mismatch negativity (MMN). The MMN is one of the most commonly used ERPs and provides an electrophysiological index of auditory change or deviance detection. Moreover, MMN has been positioned as a potentially promising biomarker candidate for the diagnosis and prediction of the outcome of schizophrenia. Dysfunction of neural receptors has been linked to the etiopathology of schizophrenia or the induction of psychophysiological anomalies similar to those observed in schizophrenia. Stimulusspecific adaptation (SSA) is a neural mechanism that contributes to the upstream processing of auditory change detection. Auditory neurons that exhibit SSA specifically adapt their response to repetitive sounds but maintain their excitability to respond to rare ones. Thus, by studying the role of neuronal receptors on SSA, we can contribute to detangle the cellular bases of the impairments in deviance processing occurring in mental pathologies. Here, we review the current knowledge on the effect of $\mathrm{GABA}_{\mathrm{A}}$-mediated inhibition and the modulation of acetylcholine on SSA in the inferior colliculus, and we add unpublished original data obtained blocking glutamate receptors. We found that the blockade of $\mathrm{GABA}_{\mathrm{A}}$ and glutamate receptors mediates an overall increase or decrease of the neural response, respectively, while acetylcholine affects only the response to the repetitive sounds. These results demonstrate that GABAergic, glutamatergic and cholinergic receptors play different and complementary roles on shaping SSA.
\end{abstract}

(c) 2015 Elsevier B.V. All rights reserved.

\section{Overview}

Event-related potentials such as the mismatch negativity response (MMN) have been extensively used as a neurophysiological index of preattentive auditory sensory memory as it occurs in response to a sensory stimulus that violates previously established patterns of regularity (Näätänen, Paavilainen, Rinne, \& Alho, 2007). The MMN is measured as the difference between the auditory-evoked potential elicited by a repetitive sound compared with the potential elicited by a rare, unexpected sound (larger amplitude) in electroencephalographic studies. MMN has been positioned as a potentially promising biomarker candidate for the diagnosis of pathologies such as schizophrenia (Harms et al., 2014; Nagai et al., 2013) or autism spectrum

\footnotetext{
* Corresponding author at: Auditory Neurophysiology Laboratory (Lab 1), Institute of Neuroscience of Castilla y León, University of Salamanca, C/ Pintor Fernando Gallego, 1, 37007 Salamanca, Spain. Fax: +34 923294750.

E-mail address: msm@usal.es (M.S. Malmierca).

1 These authors contributed equally and will be considered co-first authors.
}

disorders, including Asperger's syndrome (e.g., O'Connor, 2012). Patients with schizophrenia exhibited a reduced ability to detect acoustic changes reflected in reduced MMN (Fisher, Grant, Smith, Borracci, Labelle, \& Knott, 2012; Hong, Moran, Du, O’Donnell, \& Summerfelt, 2012; Michie, 2001). Schizophrenia has been associated with alterations in neurotransmission as the one mediated by the NMDA ( $N$-methyl-D-aspartate) receptor (Matsuno et al., 2015). Moreover, several studies have showed that acoustic MMN is sensitive to cholinergic modulation (Dunbar et al., 2007; Knott et al., 2014; Mathalon et al., 2014; Moran, Campo, Symmonds, Stephan, Dolan, \& Friston, 2013) or to nitrous oxide $\left(\mathrm{N}_{2} \mathrm{O}\right)$ (e.g., Pang \& Fowler, 1999). In autism spectrum disorders, larger amplitudes and earlier latencies relative to control subjects have been observed in children and adults diagnosed with these disorders (Kujala et al., 2007; Lepisto et al., 2008). Genetic variation of the gene encoding for the $G_{A B A}$ receptor (GABRB3) and polymorphisms of the serotonin transporter gene (SLC6A4) have been associated with autism spectrum disorders (Devlin et al., 2005; Warrier, Baron-Cohen, \& Chakrabarti, 2013). Thus, a starting point for elucidating how alterations in neurotransmission contribute to deficits in deviance detection is to employ animal models to 
pharmacologically isolate the role of specific modulatory substances on event-related potentials or on correlated neuronal activity. Recent studies have demonstrated that MMN-like responses occur in animal models like the rat (Harms et al., 2014; Jung et al., 2013). Likewise, neurons that exhibit a specific decrement in their response to repetitive but not to rare sounds have been characterized in animals. This specialized neural response is referred to as 'stimulus-specific adaptation' (SSA). SSA is a particular type of neuronal adaptation (Pérez-González \& Malmierca, 2014) that occurs in the non-lemniscal subdivisions of the inferior colliculus (IC) (Malmierca, Cristaudo, Perez-Gonzalez, \& Covey, 2009), auditory thalamus (Antunes, Nelken, Covey, \& Malmierca, 2010) and primary auditory cortex (Ulanovsky, Las, \& Nelken, 2003). Thus, MMN reflects the differential population coding of repetitive and rare sounds, while the SSA is a response feature that allows a neuron to differentially respond to repetitive and rare sounds. SSA is thought to contribute to the upstream processing of deviant and repetitive signals reflected in event-related potentials as the MMN (Escera \& Malmierca, 2014; Malmierca, Sanchez-Vives, Escera, \& Bendixen, 2014). Cellular mechanisms underlying SSA are likely to act at the sites of synaptic input on IC neurons and those might include synaptic depression and/or facilitation or inhibition. Moreover, several studies have demonstrated that different neuromodulators disinhibit neural circuits representing a mechanism for gating excitatory and inhibitory synaptic plasticity (reviewed in Froemke, 2015). For example, acetylcholine transiently disrupts the excitatory-inhibitory balance underlying neural receptive fields (Froemke et al., 2013; Froemke, Merzenich, \& Schreiner, 2007). Thus, recent work in our laboratory has focused on the effect of blocking or activating putative excitatory, inhibitory and neuromodulatory inputs on IC neurons exhibiting SSA. In the following, we will first describe hitherto unpublished original data obtained blocking glutamate receptors and then we will review our previous work on the effect of GABA ( $\gamma$-aminobutyric acid) mediated inhibition (Pérez-González, Hernandez, Covey, \& Malmierca, 2012; Pérez-González \& Malmierca, 2012) and the modulation of acetylcholine (ACh) on SSA (Ayala \& Malmierca, 2015).

\section{Excitatory, inhibitory, and cholinergic inputs to the IC}

The IC is the main auditory midbrain center (Malmierca, 2004) and is characterized by the convergence of ascending and descending auditory projections. Hence, multiple excitatory, inhibitory and modulatory inputs converge onto single IC neurons (Ito \& Oliver, 2010, 2012) that also receive neuromodulatory inputs from multiple sources (for a review, see Duque, Ayala, \& Malmierca, 2015).

Excitatory inputs to the IC are made of glutamatergic projections and arise from the ventral and dorsal cochlear nuclei, lateral and medial superior olive and ventral nucleus of the lateral lemniscus (Kelly \& Caspary, 2005; Malmierca, 2004, 2015) (Fig. 1). The excitatory neurotransmission in the auditory midbrain is mostly mediated through glutamatergic receptors. Ionotropic glutamate receptors mediate excitatory input at most nuclei in the ascending auditory pathway including the IC. For example, recordings in brain slices of the IC after electrical stimulation of the lateral lemniscus fibers demonstrated that there were two distinct components of the excitatory responses (Ma, Kelly, \& Wu, 2002): a rapid, short latency component that was mediated by AMPA ( $\alpha$-amino3-hydroxy-5-methyl-4-isoxazolepropionic acid) receptors, and a component with longer latency and duration that was mediated by NMDA receptors. NMDA receptors have been associated with the generation of MMN (Korostenskaja, Nikulin, Kicic, Nikulina, \& Kahkonen, 2007; Schmidt, Diaconescu, Kometer, Friston, Stephan, \& Vollenweider, 2013; Tikhonravov et al., 2010, 2008; Wacongne,

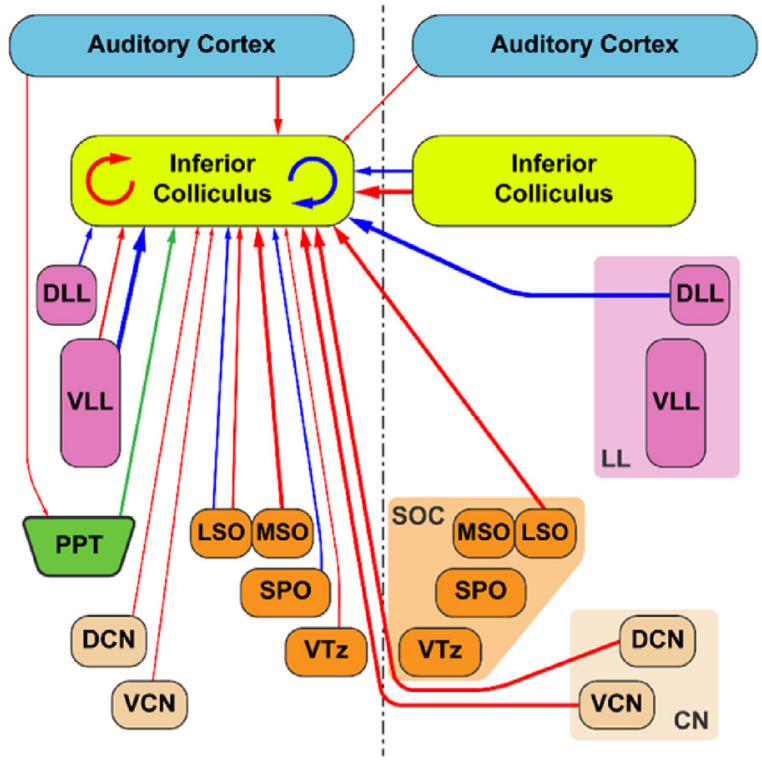

Fig. 1. Schematic diagram of the excitatory (red), inhibitory (blue) and cholinergic (green) projections to the inferior colliculus. The thickness of the lines denotes the strength of the inhibitory and excitatory projections. The vertical dashed line indicates the midline. MGB: medial geniculate body; DLL, VLL: dorsal and ventral nucleus of the lateral lemniscus (LL), respectively; PPT: pedunculopontine tegmental nucleus; SOC: superior olivary complex; LSO, MSO: lateral and medial superior olive, respectively; VTz, ventral nucleus of the trapezoid body; SPO: superior periolivary nucleus; DCN, VCN: dorsal and ventral subdivisions of the cochlear nucleus (CN). Modified from (Malmierca, 2004). For interpretation of the references to color in this figure legend, the reader is referred to the web version of this article.)

Changeux, \& Dehaene, 2012). Interestingly, Umbricht, Schmid, Koller, Vollenweider, Hell, and Javitt (2000) applied NMDA antagonists to human volunteers and found a reduced MMN, similar to that previously found in schizophrenia (Catts et al., 1995; Javitt, Steinschneider, Schroeder, \& Arezzo, 1996; Näätänen \& Michie, 1979; Todd, Michie, Schall, Karayanidis, Yabe, \& Naatanen, 2008). In a recent study, Kompus et al. (2015) found that healthy individuals with increased indicators of glutamatergic neurotransmission presented shorter latencies to MMN for changes in sound duration. But animal studies are controversial. While Farley, Quirk, Doherty, and Christian (2010) found that SSA in auditory cortical neurons of rats was insensitive to the systemic application of NMDA antagonists, Featherstone et al. (2014), using a probably more sensitive murine model with a heterozygous alteration of the NMDA receptor NR1 subunit gene, reported a significant reduction in the expression of NMDA receptors that caused a distinct decrement of MMN. The discrepancy of the effects of NMDA receptors on MMN and SSA is intriguing. In the following sections, we will present original data trying to shed light on the possible links between NMDA (and AMPA) receptors and SSA.

Inhibitory inputs to the IC are mediated by GABA and glycine (Merchán, Aguilar, Lopez-Poveda, \& Malmierca, 2005; Oliver, 1984; Riquelme, Saldaña, Osen, Ottersen, \& Merchán, 2001; Saint Marie \& Baker, 1990). Glycinergic inhibition arises from the ipsilateral lateral superior olive and the ventral nucleus of the lateral lemniscus (Riquelme et al., 2001; Vater, Covey, \& Casseday, 1997) while GABAergic inputs arise from several extrinsic and intrinsic sources (Fig. 1). Extrinsic GABAergic sources include the lateral superior olive and the superior paraolivary nucleus (Kulesza, Spirou, \& Berrebi, 2003), ventral nucleus of the lateral lemniscus ipsilaterally, and the dorsal nucleus of the lateral lemniscus bilaterally (Adams \& Mugnaini, 1984; Li \& Kelly, 1992; Saldaña \& Merchán, 1992; Zhang, Li, Kelly, \& Wu, 1998). In addition, local IC GABAergic neurons (Gonzalez-Hernandez, Mantolan-Sarmiento, Gonzalez-Gonzalez, \& 
Perez-Gonzalez, 1996; Hernández, Espinosa, Pérez-González, \& Malmierca, 2005; Merchán, Aguilar, Lopez-Poveda, \& Malmierca, 2005) affect neural responsiveness through intrinsic or commissural projections (Malmierca, Hernández, Falconi, Lopez-Poveda, Merchán, \& Rees, 2003; Malmierca, Hernández, \& Rees, 2005). The GABAergic-mediated inhibition acts on $G_{A B A}$ and $G_{A B}$ receptors expressed across IC neurons. The pharmacological manipulation of the $\mathrm{GABA}_{\mathrm{A}}$ receptors significantly affects soundevoked responses (Faingold, Boersma Anderson, \& Caspary, 1991; Yang, Pollak, \& Resler, 1992), modifying different response properties including frequency tuning (Le Beau, Rees, \& Malmierca, 1996; LeBeau, Malmierca, \& Rees, 2001; Palombi \& Caspary, 1996; Yang et al., 1992), response to sound intensity (Sivaramakrishnan, Sterbing-D’Angelo, Filipovic, D’Angelo, Oliver, \& Kuwada, 2004), coding of interaural time and level differences (D'Angelo, Sterbing, Ostapoff, \& Kuwada, 2005; Fujita \& Konishi, 1991; Vater, Habbicht, Kossl, \& Grothe, 1992) as well as IC responsiveness to binaural motion cues (McAlpine \& Palmer, 2002).

Neuromodulatory influences to the IC include those mediated by noradrenergic (Hormigo, Horta Junior Jde, Gomez-Nieto, \& Lopez, 2012; Klepper \& Herbert, 1991), serotoninergic (Hurley \& Sullivan, 2012; Obara, Kamiya, \& Fukuda, 2014; Ramsey, Sinha, \& Hurley, 2010; Thompson \& Thompson, 2009), dopaminergic (Gittelman, Perkel, \& Portfors, 2013; Olazabal \& Moore, 1989) and cholinergic projections (Schofield, 2010). The cholinergic inputs originate in the pontomesencephalic tegmentum, that includes the pedunculopontine and laterodorsal tegmental nucleus. Those cholinergic neurons are innervated by auditory cortical neurons from layer $\mathrm{V}$ (Schofield, 2010; Schofield \& Motts, 2009) (Fig. 1). Very little is known about the type and distribution of the cholinergic receptors on IC neurons and their functional impact on neural firing. Overall, both cholinergic receptors (muscarinic and nicotinic) are expressed in the IC (Cortes \& Palacios, 1986; Morley \& Kemp, 1981) and they are likely to be pre- as well as postsynaptic receptors (reviewed in Thiele, 2013). Earlier studies revealed diverse effects of ACh on IC neural responses (potentiated and suppressed sound-evoked activity) suggesting ACh exerts a complex and dynamic modulation (Farley, Morley, Javel, \& Gorga, 1983; Habbicht \& Vater, 1996; Watanabe \& Simada, 1971).

\section{Experimental approach}

In vivo iontophoresis is a powerful technique that allows the pharmacological manipulation of neuronal responses at the synaptic level. Therefore, it is an excellent choice to determine the role of synaptic inputs on sensory processing, since it allows maintaining intact the whole neural circuitry. This technique consists in the minute release of different and selective compounds (agonists, antagonists, etc.) very close (usually around $20-40 \mu \mathrm{m}$ ) to the recorded neuron to reversibly block or activate specific receptors. Recordings are performed using so-called piggy-back electrodes, which are made of a recording electrode (usually a glass or tungsten electrode) attached to a multibarrel glass micropipette (Fig. 2A). The glass barrels contain the neuroactive substances that are retained and ejected by the application of current injections (in the range of nA) (Perkins \& Stone, 1983; Windhorst et al., 1999). Then, different neuroactive compounds can be co-released to simulate the natural mixture of neurotransmitters and neuromodulators that occurs in natural conditions.

To study auditory SSA, one pair of frequencies usually surrounding the characteristic frequency of each neuron (frequency of a sound capable of evoking a response at the lowest sound intensity) is chosen from its frequency response area (FRA; spectrum of frequencies and intensities that evoke a suprathreshold response, Fig. 2B). The frequencies are chosen so that both evoke a similar response strength (Antunes et al., 2010) when they are randomly played during the FRA construction. Those frequencies are presented under the 'oddball paradigm' widely used in human studies (Näätänen, 1992) and more recently in animal studies (Ulanovsky et al., 2003). The oddball paradigm consists in the presentation of one frequency at high probability of occurrence (standard tone), while the second frequency is presented rarely (deviant tone). Afterwards, the relative probabilities of the pair of frequencies are switched to validate that the differential responses are in fact due to the probability of the stimulus and not to the physical difference between the frequencies used (Fig. 2C). The amount of SSA to both frequencies is estimated by the common SSA index (CSI) which reflects the normalized difference in the evoked response between deviant and standard tones, with values between -1 and 1 . Positive CSI values indicate a stronger response to deviant tones while negative CSIs indicate a stronger response to standard tones. A CSI value of zero reflects an equal response to deviant and standard tones (Fig. 2D). By repeating this paradigm before, during and after the iontophoretic application of specific drugs, we can dissect the contribution and specificity of different receptors on the neural response to deviant and to standard tones and its effect on CSI, i.e., we can determine what role, if any, they play on SSA.

\section{Effect of glutamatergic antagonists on SSA}

In order to study the effect of glutamate on SSA, we recorded from 37 neurons in the IC using an oddball stimulation paradigm, as described above, before, during and after the microiontophoretic application of either CPP (3-(2-carboxypiperazin-4-yl)propyl-1phosphonic acid) or NBQX (2,3-dihydroxy-6-nitro-7-sulfamoylbenzo[f]quinoxaline-2,3-dione). These drugs are selective antagonists of the NMDA or AMPA/kainate glutamate receptors, respectively. Here, we report for the first time a total of 53 applications of drugs, consisting of 28 applications of CPP and 25 applications of NBQX. In 15 cases, both drugs were tested sequentially on the same neuron, so the second drug was applied after the effects of the first one had disappeared. At the beginning of each experiment we isolated a single unit, and then we played trains of stimuli in an oddball paradigm, in order to obtain the baseline response of the neuron. We continued recording the responses to this stimulation protocol during the local application and afterwards until the neuronal responses returned to their baseline levels.

\subsection{Effect on spike counts}

The application of both CPP and NBQX produced a significant decrement on the neuronal response, measured as spike counts. Since we measured two sound frequencies for each drug application, we took 56 measurements of the effect of CPP (Fig. 3A), and most of those ( 47 for standards, 43 for deviants) showed a significant decrease in the number of spikes evoked per trial (Bootstrapping, 95\% confidence interval). The application of CPP caused an average decrement of $\sim 60 \%$ on the responses to both standard and deviant stimuli (Fig. 3A). The measurements for the application of glutamate antagonists are summarized in Table 1.

The application of NBQX also resulted in a decrement of the spike counts (Fig. 3B). In this case, we obtained 50 measurements during the application of NBQX, where 40 standard cases and 33 deviant cases showed a significant decrease in the number of spikes evoked per trial. The application of NBQX caused an average decrement of $\sim 70 \%$ on the responses to the standard stimuli (Fig. 3B). In contrast (Fig. 3B), the application of NBQX caused an average decrement of $\sim 54 \%$ on the responses to deviant stimuli.

As previously reported (Malmierca et al., 2009), the responses before the application of drugs were stronger for deviant stimuli 
A

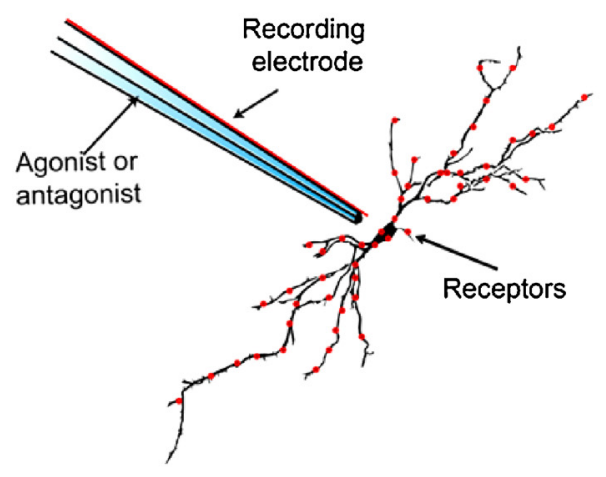

B

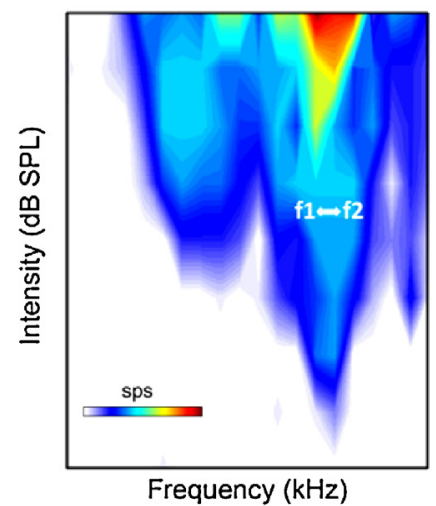

C

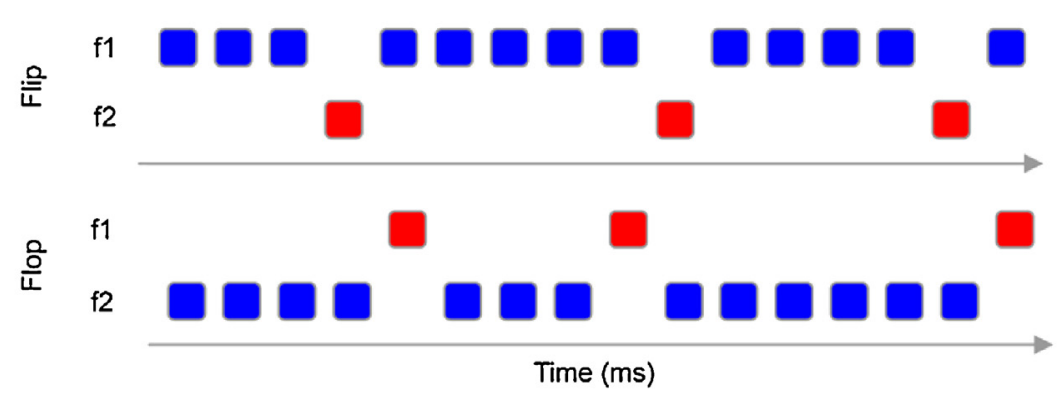

D
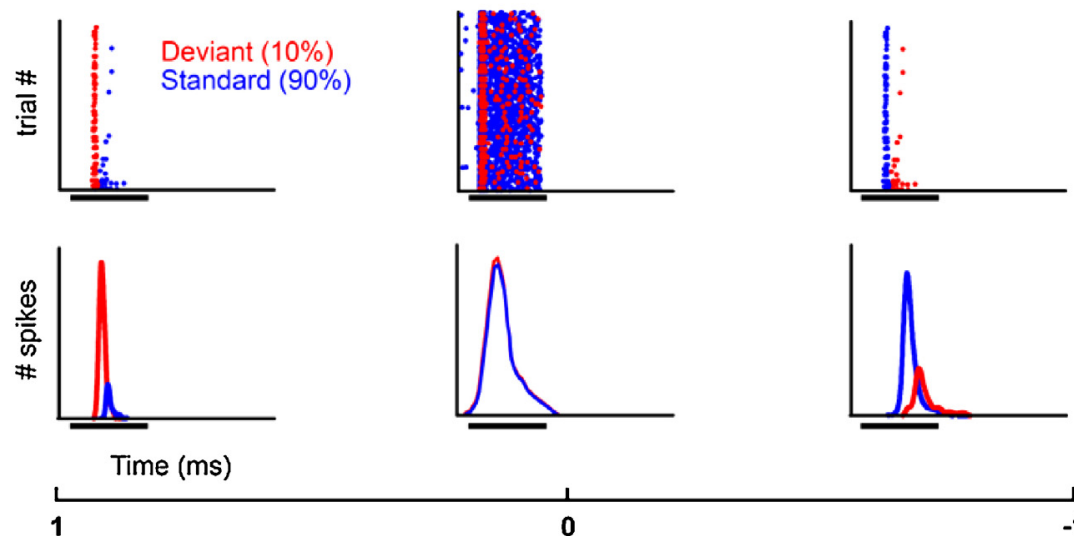

0

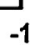

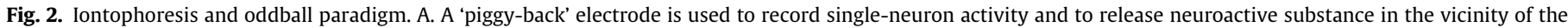

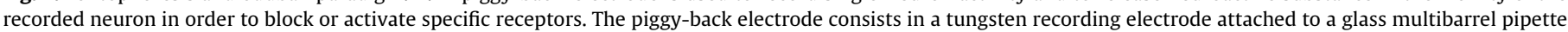

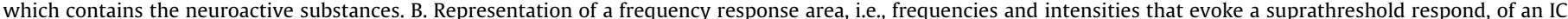

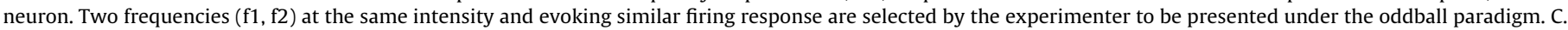

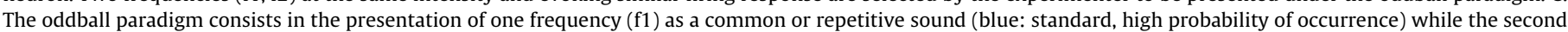

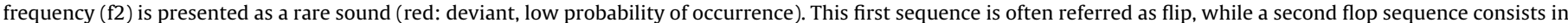

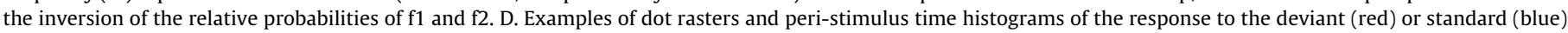

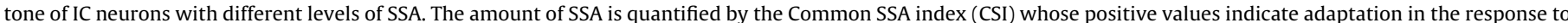

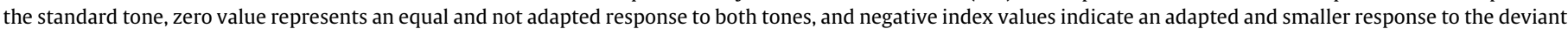
sound. For interpretation of the references to color in this figure legend, the reader is referred to the web version of this article.)

than for standard stimuli (Fig. 3C and D). The reduction of the spike rates due to the effect of both drugs was significant (2-way ANOVA) for the standard stimuli as well as for the deviant stimuli, as shown in Fig. 3C and D.

\subsection{Effect on first spike latency}

We found that the first spike latency (FSL) of the responses to standard stimuli was larger than in response to deviant stimuli, which is consistent with previous studies (Malmierca et al., 2009).
The application of CPP produced a significant increment of the FSL (Bootstrapping, 95\% confidence interval) in 20/56 cases in response to the standard stimuli (Fig. 4A) and 26/56 cases in response to the deviant stimuli (Fig. 4A). The effect of the FSL was larger during the application of NBQX, which caused a significant increment in 24/50 standard cases (Fig. 4B) and 30/50 deviant cases (Fig. 4B). Moreover, NBQX not only increased the latency of more neurons, but also the increment was larger. While some neurons experienced a significant increment of latency during the application of CPP, it did not cause a significant change at the population level (2-way ANOVA) 

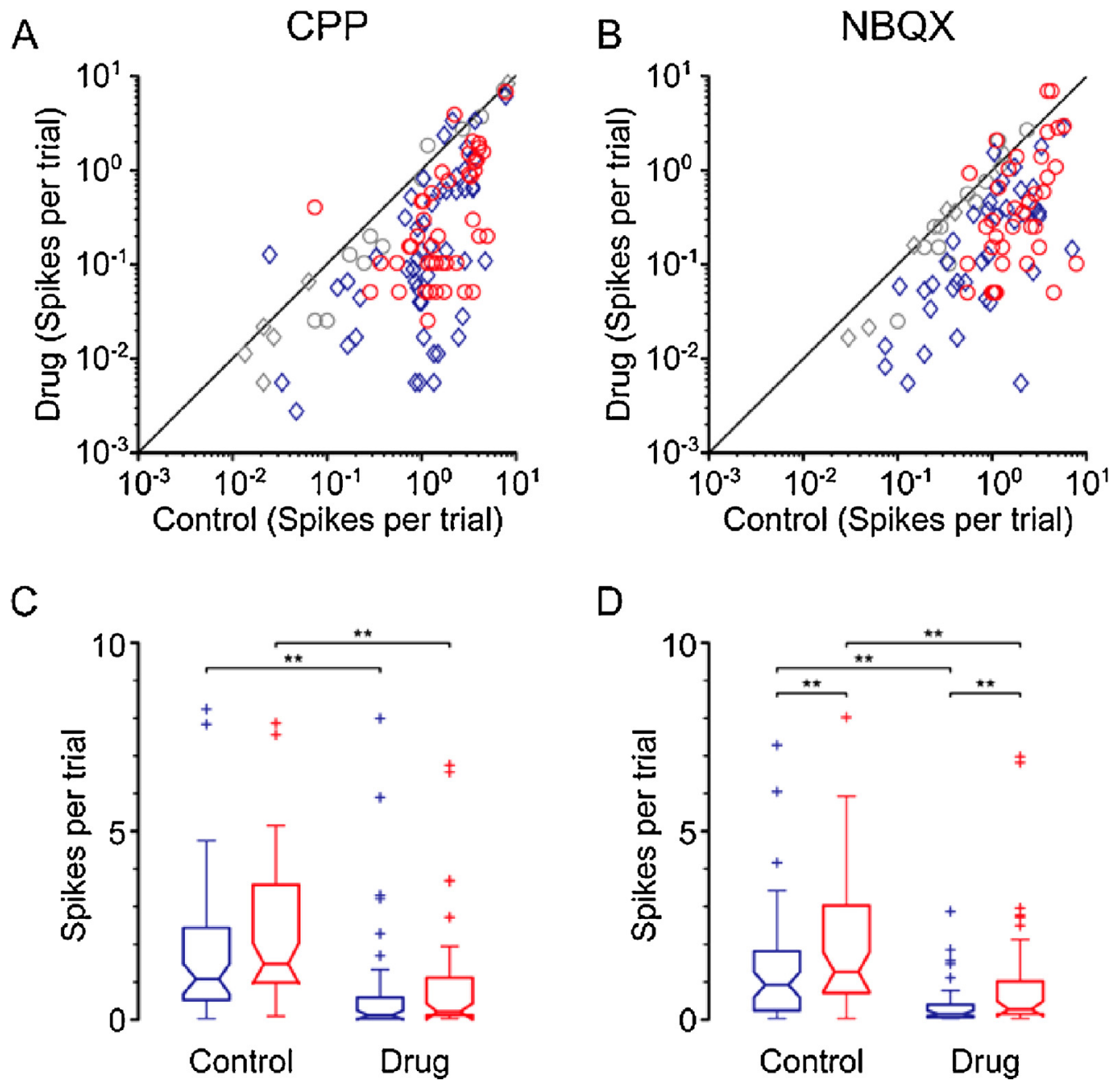

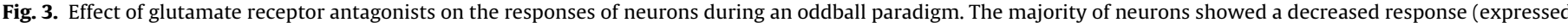

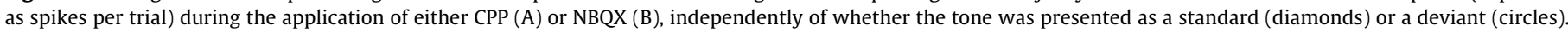

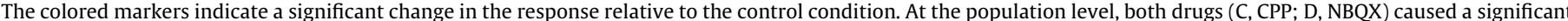

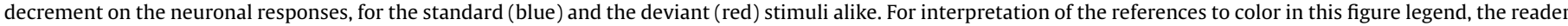
is referred to the web version of this article.)

in response to standard nor deviant stimuli (Fig. 4C, Table 1). In contrast, the effect of NBQX (Fig. 4D, Table 1) was large enough to be significant at the population level, for both standard and deviant stimuli.

\subsection{Effect on SSA index}

The effect of the drugs on the common SSA index (CSI) was very variable. We recorded from units with a very large range of baseline CSI, from -0.06 up to 0.93 (Fig. $5 \mathrm{~A}$ and B). Out of the 28 units tested with CPP, 20 showed an increment of the CSI during the application, while 8 showed a decrement. In the case of NBQX, in 13 out of 25 units, the CSI increased during the application of the drug, while in 12 units it decreased. At the population level, both drugs tended to increment of the CSI, $\sim 0.1$ in the case of CPP (Fig. $5 \mathrm{~A}$ ) and $\sim 0.05$ in the case of NBQX (Fig. 5B). Nevertheless, due to the high individual variability, the effects of the drugs on the CSI at the population level were not significant (2-way ANOVA, Fig. 5C), probably because the effects on individual neurons were averaged out. The values found for the frequency-specific $S S A$ index $\left(\mathrm{SI}_{\mathrm{f}}\right)$ were very similar to those obtained for the CSI (Table 1).

\subsection{Effect on the time course of adaptation}

We analyzed separately the temporal dynamics of adaptation to the standard and deviant stimuli across the population, during the oddball paradigm (Fig. 6). As in previous studies (PérezGonzález et al., 2012), the time course of adaptation for the standard stimuli was fitted by a double exponential function $f(t)=A_{\mathrm{ss}}+A_{r} \times$ $e^{-t / \tau(r)}+A_{s} \times e^{-t / \tau(s)}$. This function contains rapid and slow decay components, before reaching a steady-state.

The goodness of fit of the double exponential function to the responses to standard stimuli was good, with $r^{2}>0.65$ in all cases. As expected from the spike count results, the overall response was smaller during the application of the drugs (Fig. 6A and B), mainly due to a smaller steady-state component $\left(A_{\mathrm{ss}}\right)$ (Fig. $6 \mathrm{~A}$ and $\mathrm{B}$ ). The application of both drugs made the fast time constant $\left(\tau_{\mathrm{r}}\right)$ faster, especially in the case of NBQX. The application of the drugs tended to slow down the slow time constant $\left(\tau_{\mathrm{s}}\right)$ in the case of the CPP application, but not for NBQX.

The adaptation to the deviant stimuli was very low under the control (Fig. 6C and D; red dots) and effect (Fig. 6C and D; yellow dots) conditions, for both drugs. The time course of adaptation for deviant stimuli was best fitted to a linear function $f(t)=a+b t$, and in 

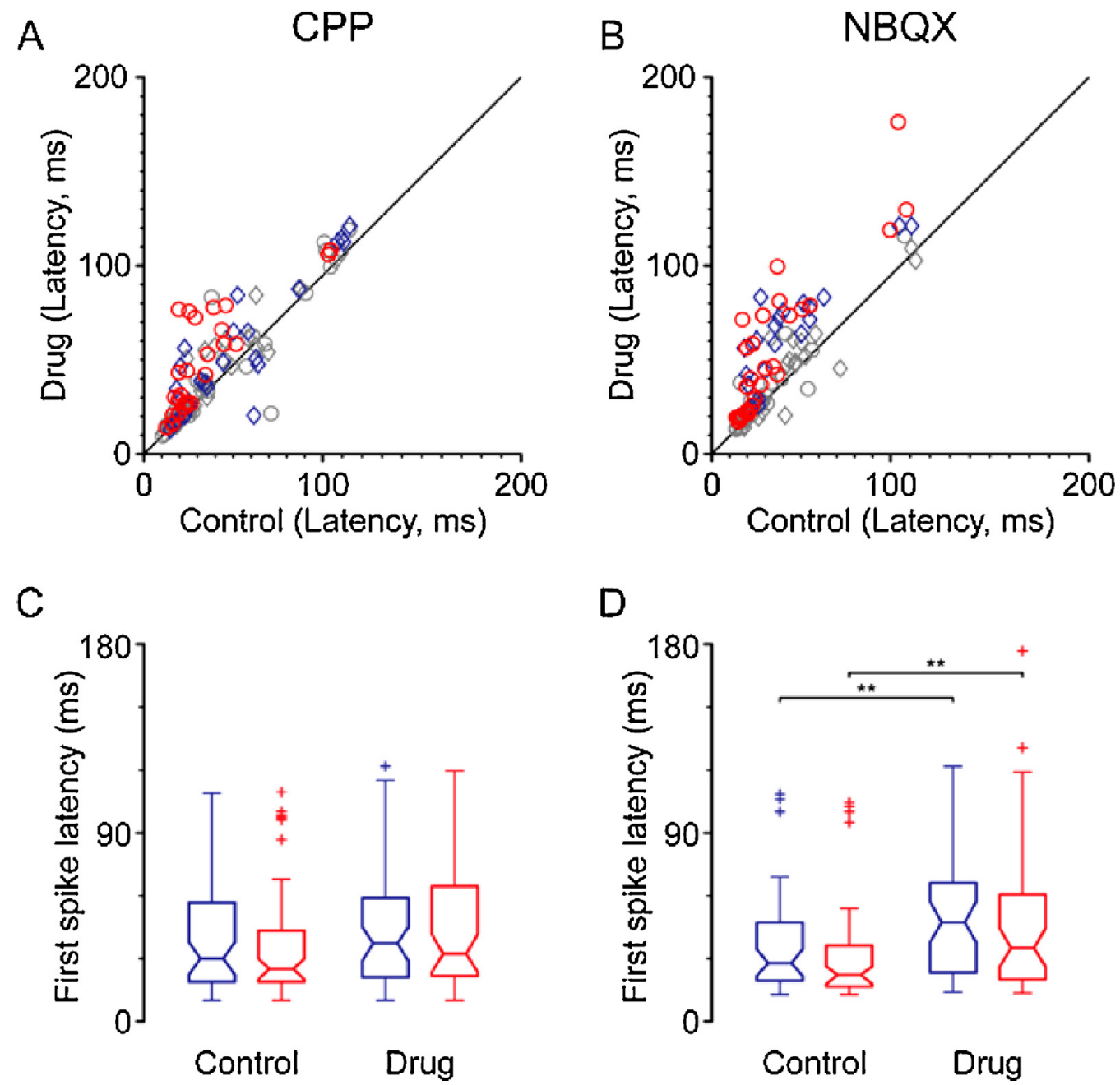

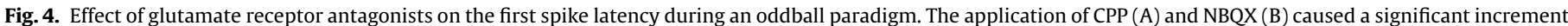

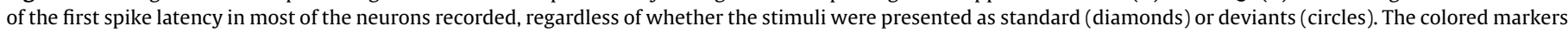

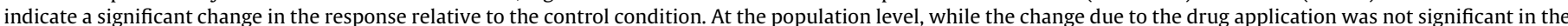

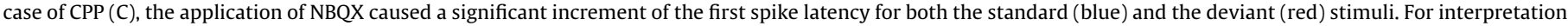
of the references to color in this figure legend, the reader is referred to the web version of this article.)
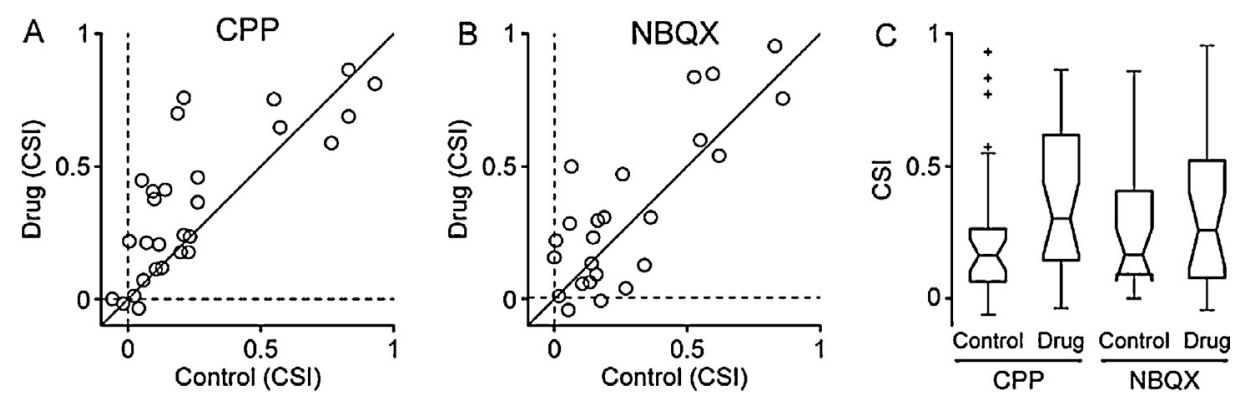

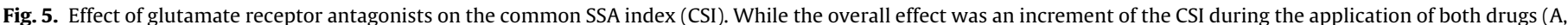
CPP; B, NBQX), at the population level (C) the amount of increment was not statistically significant.

none of the cases the slope coefficient $(b)$ was significantly different to zero, effectively indicating a lack of adaptation across trials. The main effect of the drugs was to reduce the constant component ( $a$ ), to roughly the half (Table 1 ).

\section{Effect of GABAergic inhibition on SSA}

The first attempt to disentangle how the synaptic inhibitory inputs shape SSA was carried out by (Pérez-González et al., 2012).
This study manipulated the GABAergic inhibition that adapting neurons in the IC receive to address whether the adaptation to the standard tone was generated by the activation of the $G A B A_{A}$ receptors. The blockade of the $G_{A B A_{A}}$ receptors using the specific antagonist (gabazine) exerted a profound effect on the magnitude and dynamics of SSA by increasing the neural firing rate and by altering the temporal response pattern. An example of the typical effect exerted by gabazine on the firing of adapting IC neurons is illustrated in Fig. 7. This neuron exhibited significant SSA 
Table 1

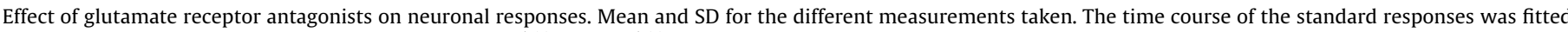

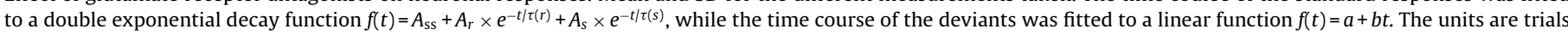
(equivalent to $250 \mathrm{~ms}$ ) for $\tau_{\mathrm{r}}$ and $\tau_{\mathrm{s}}$, and spikes per trial for $A_{\mathrm{ss}}, A_{\mathrm{r}}$ and $A_{\mathrm{s}}$.

\begin{tabular}{|c|c|c|c|c|}
\hline & \multicolumn{2}{|l|}{$\mathrm{CPP}(n=28)$} & \multicolumn{2}{|l|}{$\operatorname{NBQX}(n=25)$} \\
\hline & Control & Effect & Control & Effect \\
\hline \multicolumn{5}{|c|}{ Spikes per trial } \\
\hline Standard & $1.628 \pm 1.707$ & $0.634 \pm 1.426^{*}$ & $1.321 \pm 1.529$ & $0.384 \pm 0.564^{*}$ \\
\hline Deviant & $2.187 \pm 1.791$ & $0.866 \pm 1.416^{*}$ & $2.002 \pm 1.747$ & $0.917 \pm 1.487^{*}$ \\
\hline \multicolumn{5}{|c|}{ First spike latency (ms) } \\
\hline Standard & $40.257 \pm 28.656$ & $45.478 \pm 30.933$ & $36.926 \pm 24.200$ & $49.429 \pm 28.787^{*}$ \\
\hline Deviant & $36.279 \pm 26.990$ & $44.628 \pm 30.700$ & $31.166 \pm 23.261$ & $45.733 \pm 37.461^{*}$ \\
\hline CSI & $0.254 \pm 0.284$ & $0.359 \pm 0.277$ & $0.271 \pm 0.253$ & $0.324 \pm 0.299$ \\
\hline $\mathrm{SI}_{\mathrm{f}}$ & $0.235 \pm 0.292$ & $0.339 \pm 0.426$ & $0.268 \pm 0.308$ & $0.338 \pm 0.408$ \\
\hline \multicolumn{5}{|c|}{ Time course fitting (standards) } \\
\hline$\tau_{\mathrm{r}}$ & 1.883 & $1.199^{*}$ & 1.563 & $0.678^{*}$ \\
\hline$\tau_{\mathrm{s}}$ & 38.65 & 47.55 & 17.47 & 18.410 \\
\hline$A_{\mathrm{SS}}$ & 1.526 & $0.525^{*}$ & 1.283 & $0.342^{*}$ \\
\hline$A_{\mathrm{r}}$ & 2.574 & 2.234 & 2.665 & 3.533 \\
\hline$A_{\mathrm{s}}$ & 0.560 & 0.460 & 0.394 & 0.442 \\
\hline \multicolumn{5}{|c|}{ Time course fitting (deviants) } \\
\hline$a$ & 2.358 & $1.029^{*}$ & 2.134 & $0.930^{*}$ \\
\hline$b$ & -0.002 & -0.001 & -0.001 & 0.000 \\
\hline
\end{tabular}

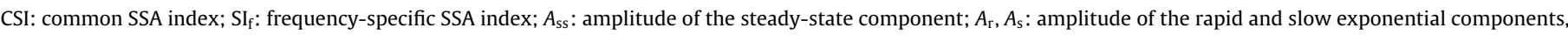
respectively; $\tau_{\mathrm{r}}, \tau_{\mathrm{s}}$ : time constant of the rapid and slow exponential components.

* Significant effect of the drug ( $p<0.05$, ANOVA; 95\% confidence interval for the fittings).

\section{CPP}
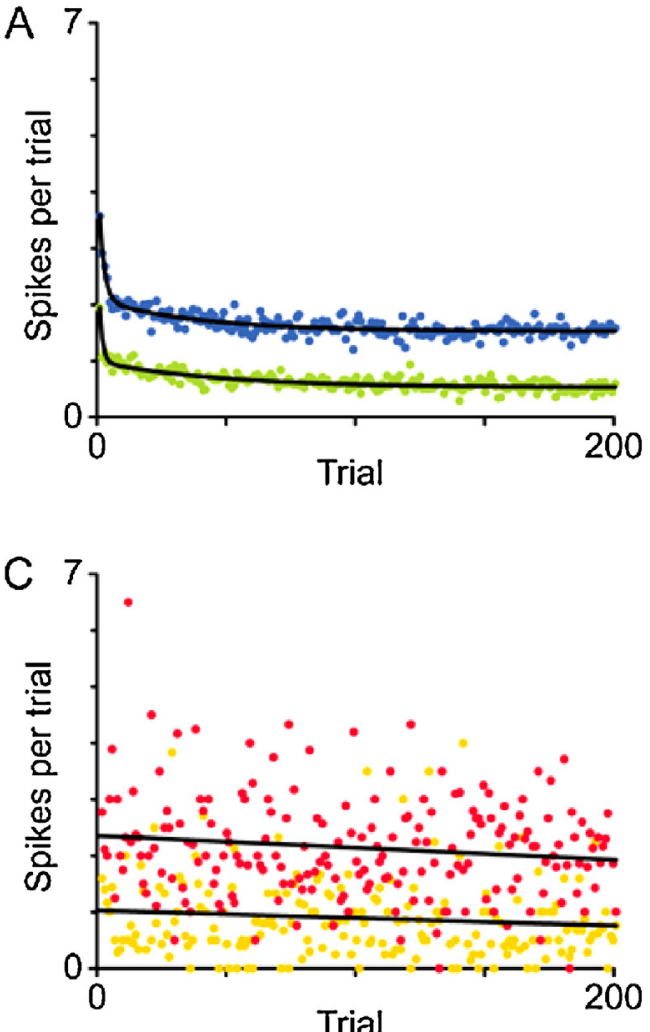

NBQX
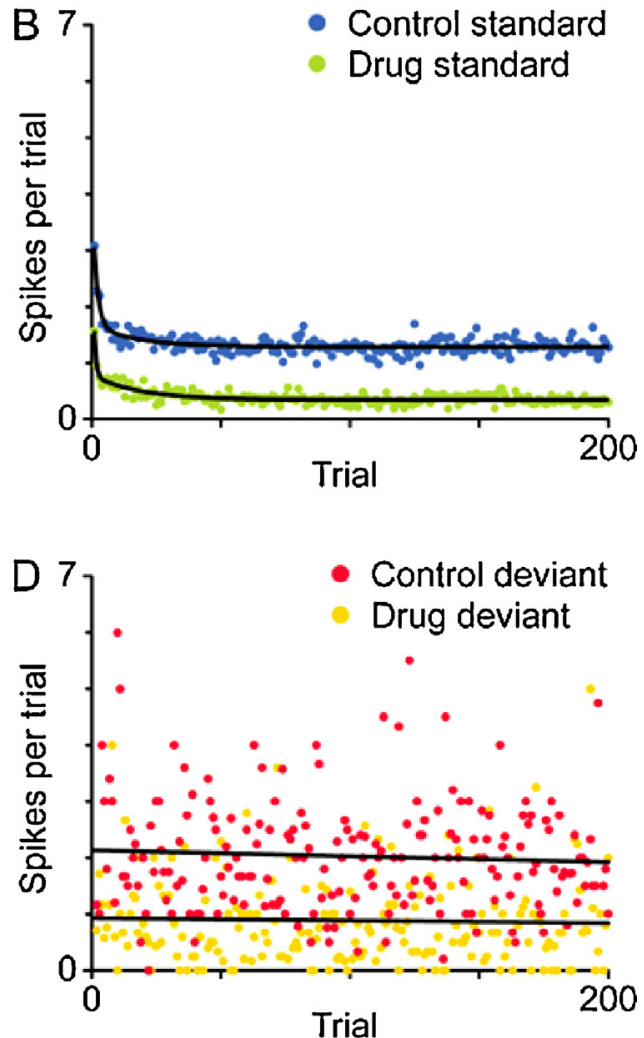

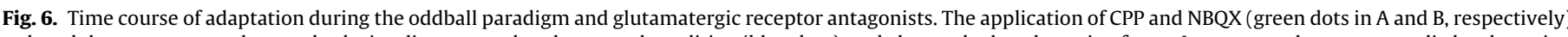

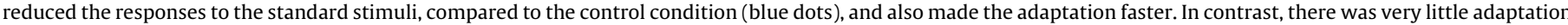

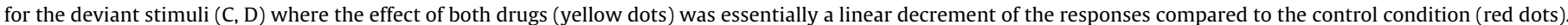

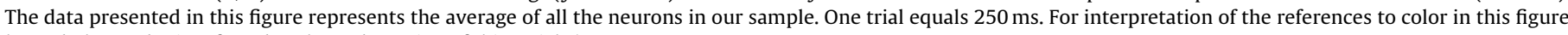
legend, the reader is referred to the web version of this article.) 
A
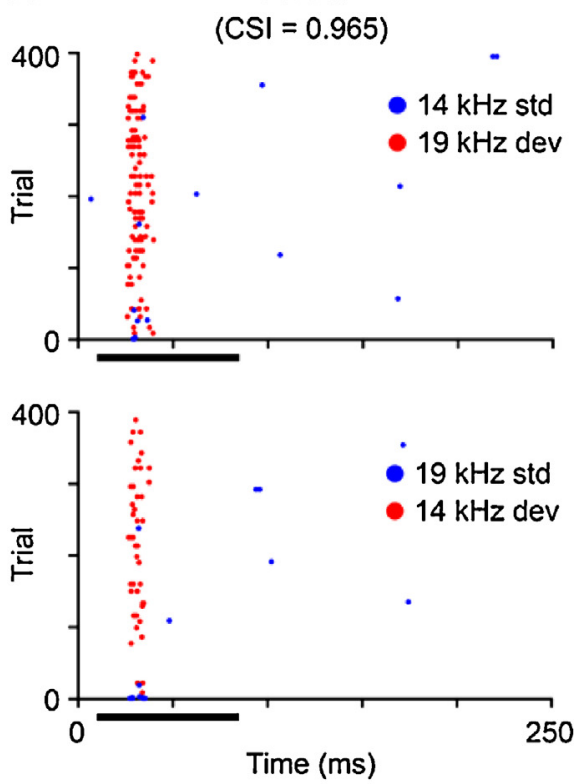

C

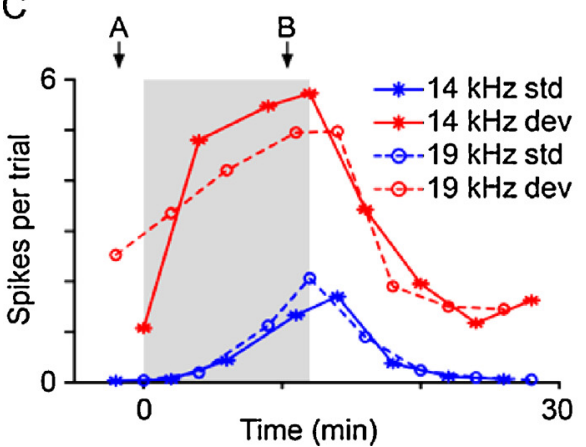

B

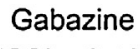

$(C S I=0.48)$
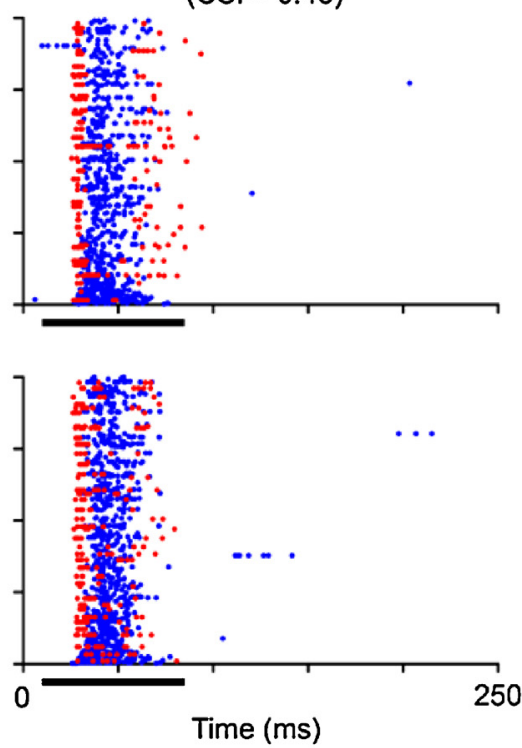

D

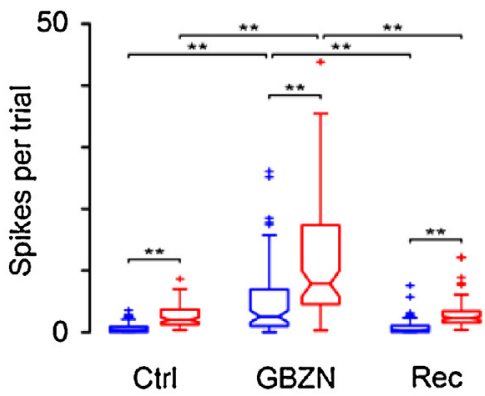

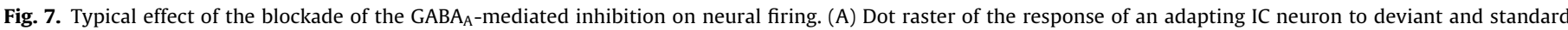

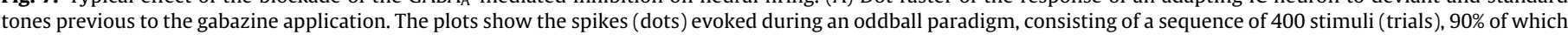

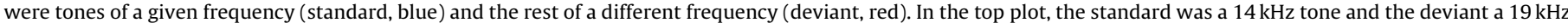

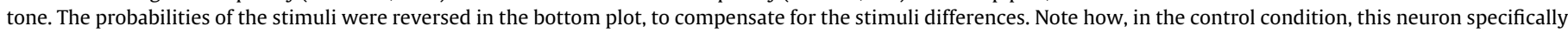

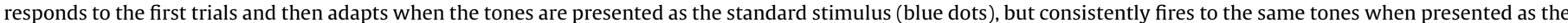

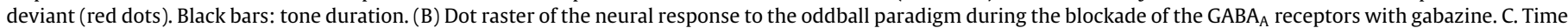

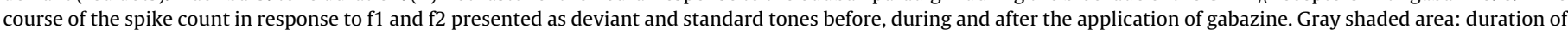

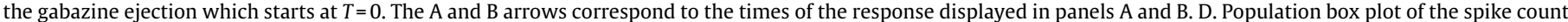

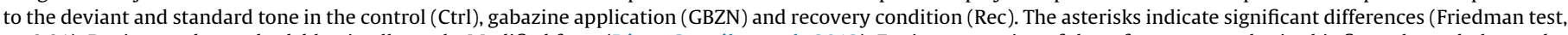

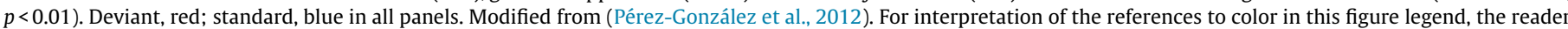
is referred to the web version of this article.)
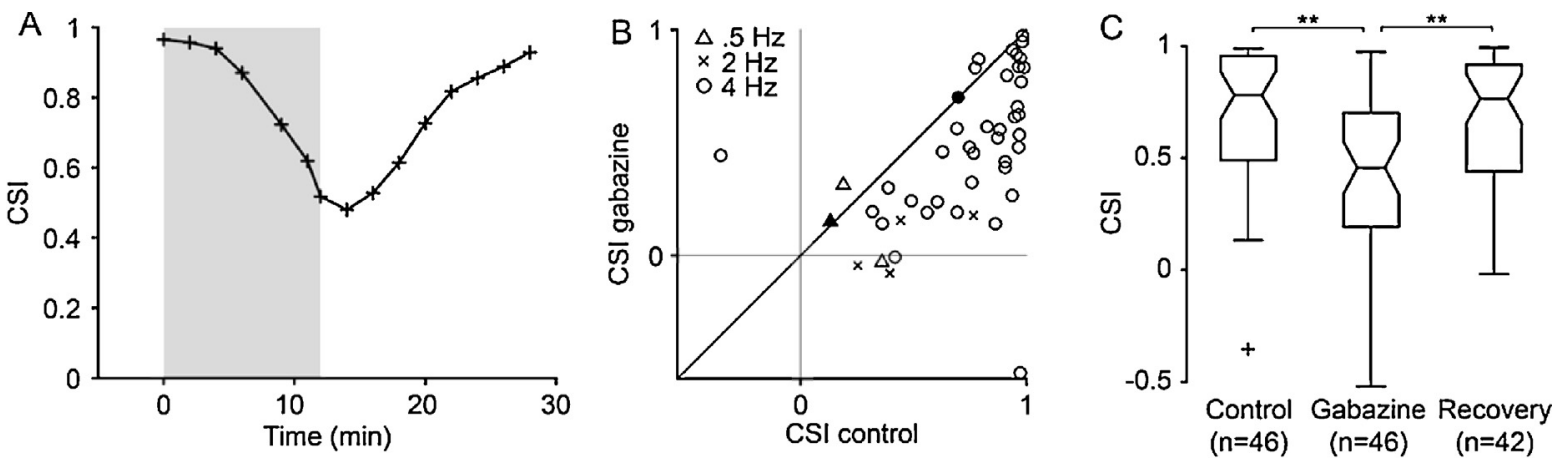

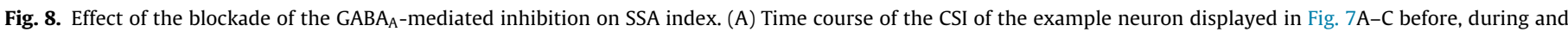

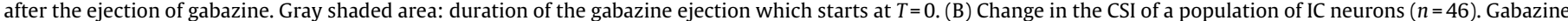

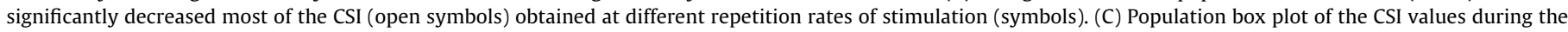
control, gabazine ejection and recovery condition. The asterisks indicate significant differences (Friedman test, $p<0.01$ ). Modified from (Pérez-González et al., 2012). 
during the control condition, i.e., previous to the gabazine application (Fig. 7A), and responded to the deviant sound presentations but quickly adapted its response to the standard tone after a few presentations. Neurons like this one exhibit shorter response latency to the deviant than to the standard tone. The overall effect of blocking $\mathrm{GABA}_{\mathrm{A}}$ receptors is an augmentation in the response strength to both, deviant and standard stimulus (Fig. 7B). As clearly shown for this neuron, the number of spikes per trial increased but the response strength remained larger for the deviant tone (Fig. 7C). Gabazine also affected the response latency to deviant and standard stimuli but did not abolish the difference between them. The median response latency to the deviant tone was significantly shortened from 19.34 (interquartile range, IQR: 6.71) to 18.24 (IQR: 3.97 ) $\mathrm{ms}$ while the latency of the response to standard tended to decrease, from 27.43 (IQR: 15.9) to 25.01 (IQR: 13.64) ms, although not significantly (Pérez-González et al., 2012). These results demonstrate that the firing pattern and response latency of these neurons depends mainly on the probability of the stimulus even during gabazine application. Another interesting finding of the study by Pérez-González \& Malmierca (2012) was that the effect of gabazine was faster on the response to the standard tone than to the deviant in some neurons (34\%) but the contrary did not occur in any IC neuron. This variability of the gabazine effect was reflected in the time course of the difference signal (difference in the neural PSTH) between the response to deviant and to standard tone (PérezGonzález \& Malmierca, 2012). Consistent with the effect of GABA in other sensory systems (Isaacson \& Scanziani, 2011; Katzner, Busse, \& Carandini, 2011), the blockade of GABAergic-mediated inhibition elicits a generalized augmentation in the neural excitability of IC neurons by increasing their evoked response to both tones regardless of their probability of occurrence (Fig. 7C and D). This enhanced responsiveness decreases the ratio between the deviant/standard responses. This is known as iceberg-effect (Isaacson \& Scanziani, 2011) and in the particular case of the application of gabazine, the simultaneous increment of the firing rate to both stimuli results in a drop of the CSI (Fig. 8), reflecting the decrease in the deviant to standard response ratio. Hence, synaptic inhibition acting on $\mathrm{GABA}_{\mathrm{A}}$ receptors regulates the strength of the response to deviant and standard tones but does not generate the SSA. These results point to the possibility that other neurotransmitters may be also participating in the generation or modulation of SSA in the IC.

\section{Effect of cholinergic modulation on SSA}

The control of attention engages different modulatory substances such as ACh (Hasselmo \& McGaughy, 2004; Passetti, Dalley, O'Connell, Everitt, \& Robbins, 2000). In humans, cholinergic manipulation affects auditory novelty detection (Klinkenberg, Blokland, Riedel, \& Sambeth, 2013; Knott et al., 2014; Moran et al., 2013). Likewise, diverse studies in animals support the notion that ACh release is necessary for the induction of auditory plasticity (Bjordahl, Dimyan, \& Weinberger, 1998; Edeline, 2012; Leach, Nodal, Cordery, King, \& Bajo, 2013; Metherate \& Weinberger, 1989). Moreover, it is likely that the mechanism of attentional modulation on sensory processing operates at multiple stages, including cortical and subcortical nuclei. To understand the relation between large scale signals as the MMN and neuronal processing at different stages along the auditory pathway, a first approach was to study the influences of ACh on single-neuron SSA responses (Ayala \& Malmierca, 2015).

The local application of $\mathrm{ACh}$ and antagonists of the muscarinic and nicotinic receptors elicited a heterogeneous and baselinedependent effect on SSA. An example of single neuron response is displayed in Fig. 9. This neuron showed an intermediate SSA index (CSI $=0.73$, Fig. 9A) that significantly decreased during the $\mathrm{ACh}$ application ( $\mathrm{CSI}=0.41$, Fig. 9B). The firing pattern of the response became more robust to the deviant and standard stimuli as shown by the temporal course of the neural firing (Fig. 9C). Interestingly, the strength of the cholinergic effect was stronger on the driving response to the standard tone than to the deviant one (Fig. 9D). In general, ACh exerts a drop in the SSA index (Fig. 10) mainly due to an augmentation of the response to the standard tone, i.e, ACh decreases response adaptation. The diminished adaptation agrees with the role of ACh in exerting a neural circuit disinhibition by transiently altering the excitatory-inhibitory balance as previously described (reviewed in Froemke, 2015). Our original study (Ayala \& Malmierca, 2015) also revealed that not all IC neurons undergo cholinergic modulation. A subset of IC neurons (partially adapting) was significantly affected by ACh and a second group of neurons (extremely and not adapting) exhibited responses insensitive to ACh (Fig. 10B). Interestingly, the non-affected neurons are the ones that lack of or exhibit extreme levels of SSA. This baselinedependent effect contrasts with the generalized drop of SSA exerted by the $G_{A B A}$-receptor blockade across neurons with different SSA levels (Fig. 8B). The same selective effect on partially adapting neurons was elicited when the muscarinic and nicotinic receptors were blocked with scopolamine and mecamylamine, respectively (Ayala \& Malmierca, 2015). Both antagonists decreased the response to the standard tone increasing the neuron's CSI. The blockade of the muscarinic receptors elicited a stronger effect indicating these receptors are mainly mediating the cholinergic modulation on SSA. In conclusion, the study by Ayala and Malmierca (2015) showed that ACh decreases the CSI of IC neurons with intermediate SSA levels by selectively decreasing the adaptation to the standard tone.

The functional significance of the cholinergic modulation on subcortical SSA can be though under the framework that indicates that ACh affects the balance between feedback and feedforward neural processing (Hasselmo \& McGaughy, 2004; Thiele, 2013). ACh increases the efficacy of feedforward/thalamocortical input connections onto excitatory neurons in layer IV (Barkai \& Hasselmo, 1994; Disney, Aoki, \& Hawken, 2007 Gil, Connors, \& Amitai, 1997; Hsieh, Cruikshank, \& Metherate, 2000; Kimura, 2000). Increased ACh levels switch sensory processing from a predominant influence of internal, corticocortical inputs to a predominant influence of external, thalamocortical inputs (Giocomo \& Hasselmo, 2007; Hasselmo \& McGaughy, 2004). Thus, the cholinergic modulation occurring on SSA responses in IC neurons might contribute to enhance the ascending processing converging in the auditory thalamus en route to the auditory cortex. Finally, it is worth to mention that the cholinergic modulation also exerts a baseline-dependent effect on the population coding of more complex acoustic regularities. In this regard, a MMN study performed in non-smoker individuals found that nicotine enhances the MMN amplitude of those individuals with low baseline amplitude while the opposite effect was elicited on those individuals with high MMN amplitudes (Knott et al., 2014). The effect of nicotine on the MMN amplitude seems to be more complex than the one elicited by the activation of the nicotinic receptors observed by Ayala and Malmierca (2015), since an increase of the CSI was noticed only in the subset of neurons with intermediate SSA level. Many factors, including the local or systemic application of the cholinergic compounds and the extent of networks affected and involved in the MMN processing and SSA responses might contribute to these dissimilarities. A second study in humans showed that nicotine alleviated the MMN amplitude attenuation induced by NMDA blockade (Knott et al., 2006). These authors suggested that nicotine might be exerting its effects by modifying the strength of excitatory and inhibitory afferent inputs to sensory cortices. Studies in animal models support this notion. For example, the activation of the nicotinic receptors regulate the thalamocortical glutamate and GABA release (reviewed in Metherate \& Hsieh, 2003). Complementary studies at different 
A

Control

$(\mathrm{CSI}=0.73)$
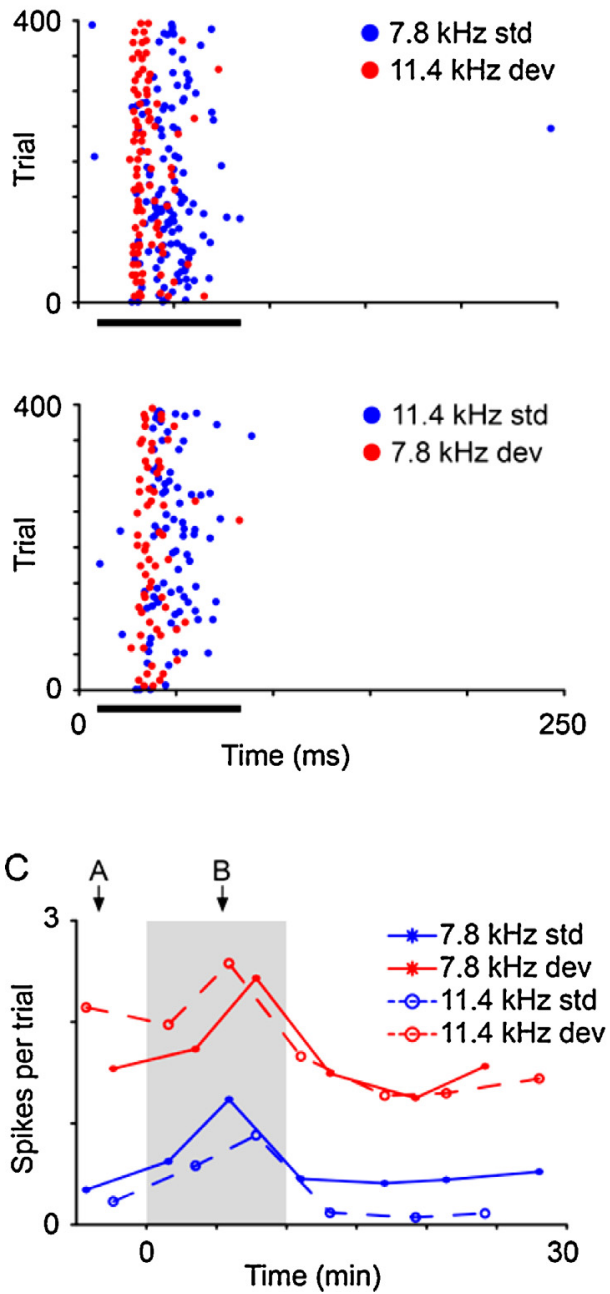

B Acetylcholine

(CSI $=0.41$ )
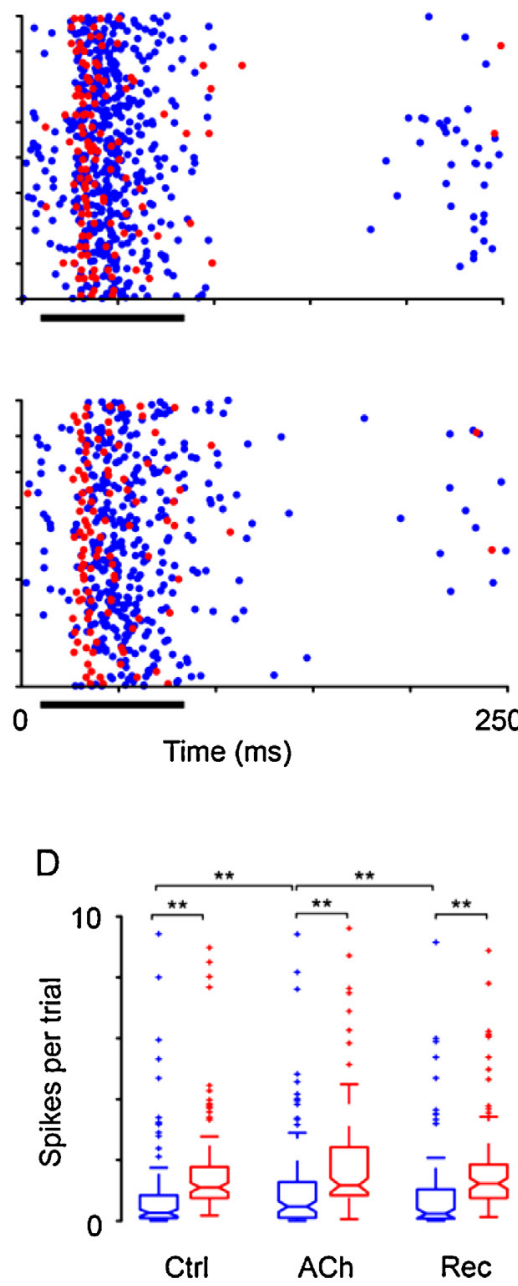

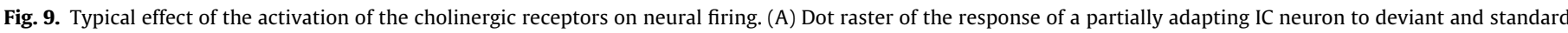

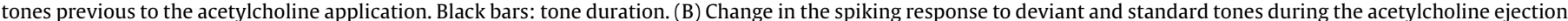

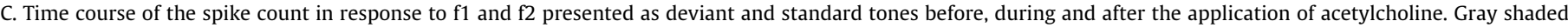

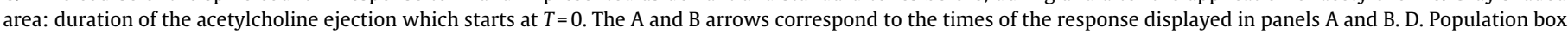

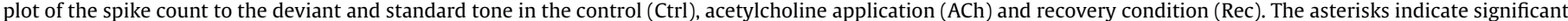

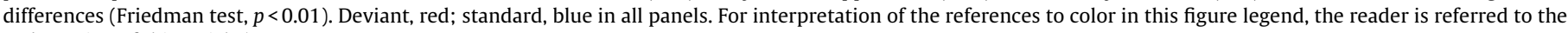
web version of this article.)
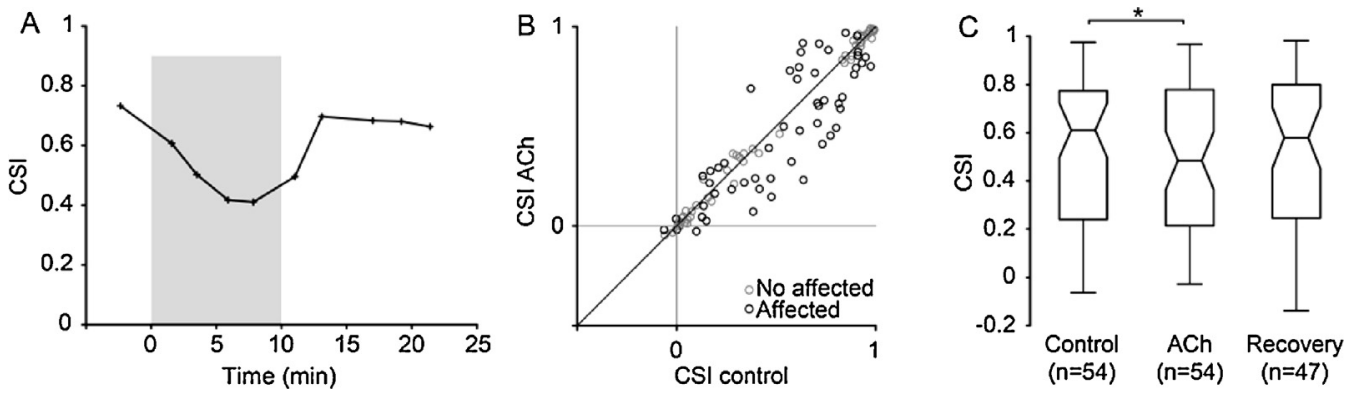

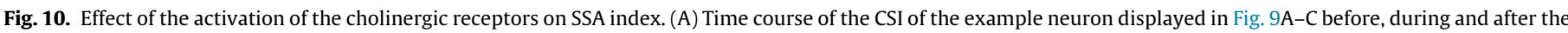

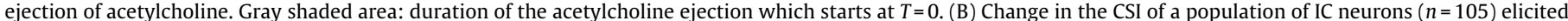

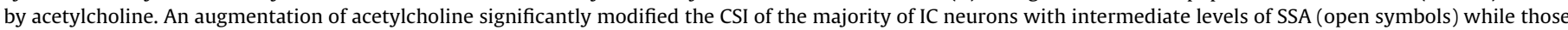

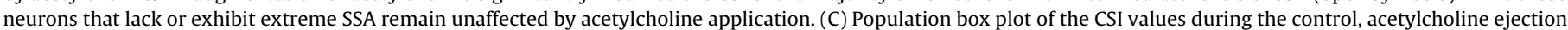

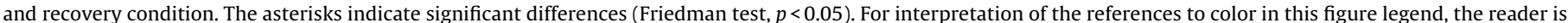
referred to the web version of this article.) 
A
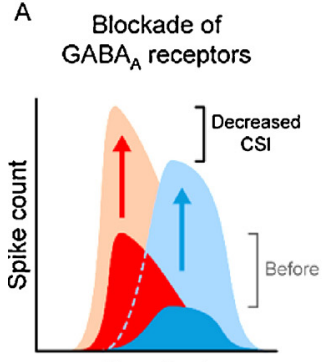

Time (ms)
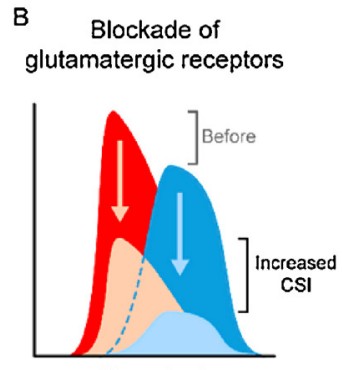

Time (ms)
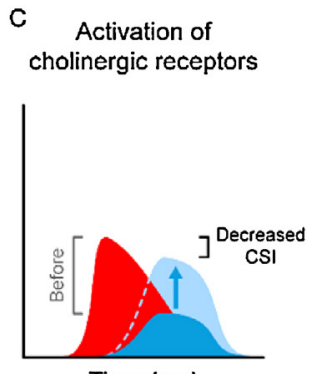

D Change in the time course of adaptation to standards

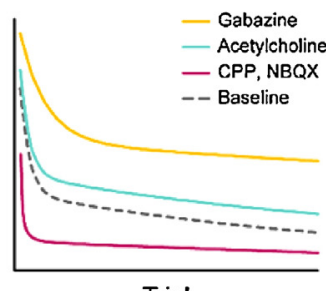

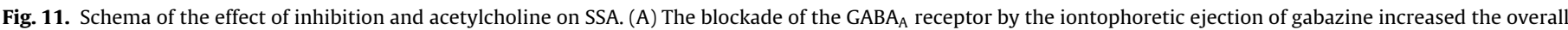

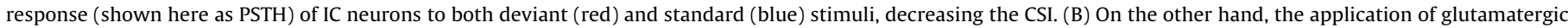

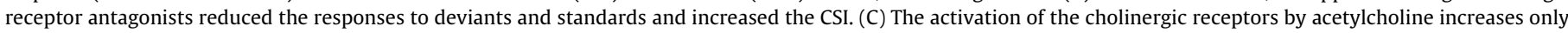

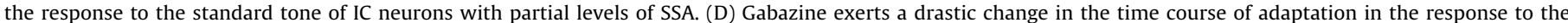

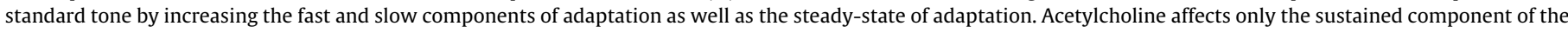

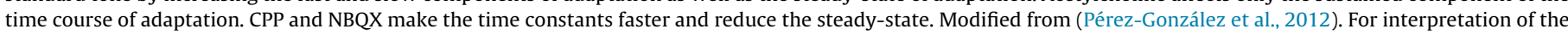
references to color in this figure legend, the reader is referred to the web version of this article.)

neural stages of processing recording single-neuron and population activity under pharmacological manipulation or under behavioral tasks known to modify the animal's attentional demands will contribute to bridge the gap between cellular and large-scale effects of neuromodulators on change detection.

\section{General discussion and final remarks}

The iontophoretic manipulation of GABAergic, glutamatergic and cholinergic receptors on SSA suggests those receptors play different roles on shaping SSA in the IC. At the population level, the blockade of $\mathrm{GABA}_{\mathrm{A}}$-mediated inhibition increases the overall spike count and decreases the response latency to deviant and standard stimuli (Fig. 11A), while the blockade of glutamatergic excitation has an opposite effect (Fig. 11B). On the other hand, the activation of cholinergic receptors exerts a delicate modulation only on the response to the standard stimuli, without affecting the timing of the response (Fig. 11C). Moreover, the different effect produced by $\mathrm{ACh}$, excitation and inhibition is reflected on the time course of the response to the standard tone. The adaptation in the response to the standard tone fits a double exponential function which includes rapid and slow decays as well as a steady-state component in the response (Pérez-González et al., 2012). While the magnitude and timing of all these three components are drastically affected by gabazine, only the magnitude of the sustained component is augmented by ACh application (Fig. 11D). The delicate modulation of ACh that selectively increases the evoked response to the standard sound without affecting the timing of the neural response contrasts with the gain control exerted by $\mathrm{GABA}_{\mathrm{A}}$-mediated inhibition in IC (Pérez-González et al., 2012) and MGB neurons (Duque, Malmierca, \& Caspary, 2014), as well as by glutamatergic excitation. From these results, we can conclude that glutamatergic excitation, $A C h$ and $G_{A B A}$-mediated inhibition produce different effects on the adaptation dynamics. While GABA and glutamate may work together to preserve an exquisite excitatory/inhibitory balance to act together as a balanced gain control system, maintaining the responses within a range that optimizes the deviant to standard ratio, ACh contributes to maintain the encoding of repetitive sounds more selectively.

Taken together, these studies highlight the differential and complementary role of putative receptors on the modulation of SSA. Moreover, these experiments contribute to reveal how glutamatergic- or other neurotransmitter-related dysfunctions linked to the etiopathology of mental illness might be affecting the upstream neural processing supporting MMN-like responses observed along the auditory pathway. Likewise, our data might indicate how such a basic auditory response as the SSA will be affected by pharmacological interventions using agonist or antagonist compounds for the clinical treatment of mental disorders like schizophrenia.

\section{Author's contribution}

Yaneri A. Ayala, David Pérez-González and Manuel S. Malmierca wrote the manuscript. David. Pérez-González performed the experiments of glutamate iontophoresis, analyzed the data and wrote the results.

\section{Financial disclosures}

The authors declare no competing financial interests.

\section{Acknowledgements}

This project was funded by the MINECO grants: BFU201343608P and PSY2013-49348-EXP the JCYL grant: SA343U14 to Manuel S. Malmierca; Yaneri A. Ayala held a CONACyT (216106) and a SEP fellowship.

\section{References}

Adams, J. C., \& Mugnaini, E. (1984). Dorsal nucleus of the lateral lemniscus: A nucleus of GABAergic projection neurons. Brain Research Bulletin, 13, 585-590.

Antunes, F. M., Nelken, I., Covey, E., \& Malmierca, M. S. (2010). Stimulus-specific adaptation in the auditory thalamus of the anesthetized rat. PLoS One, 5, e14071.

Ayala, Y. A., \& Malmierca, M. S. (2015). Cholinergic modulation of stimulus-specific adaptation in the inferior colliculus. J. Neuroscience, http://dx.doi.org/10.1523/ JNEUROSCI.0909-15.2015

Barkai, E., \& Hasselmo, M. E. (1994). Modulation of the input/output function of rat piriform cortex pyramidal cells. Journal of Neurophysiology, 72, 644-658.

Bjordahl, T. S., Dimyan, M. A., \& Weinberger, N. M. (1998). Induction of long-term receptive field plasticity in the auditory cortex of the waking guinea pig by stimulation of the nucleus basalis. Behavioral Neuroscience, 112, 467-479.

Catts, S. V., Shelley, A. M., Ward, P. B., Liebert, B., McConaghy, N., Andrews, S., et al. (1995). Brain potential evidence for an auditory sensory memory deficit in schizophrenia. The American Journal of Psychiatry, 152, 213-219.

Cortes, R., \& Palacios, J. M. (1986). Muscarinic cholinergic receptor subtypes in the rat brain. I. Quantitative autoradiographic studies. Brain Research, 362, 227-238.

D’Angelo, W. R., Sterbing, S. J., Ostapoff, E. M., \& Kuwada, S. (2005). Role of GABAergic inhibition in the coding of interaural time differences of low-frequency sounds in the inferior colliculus. Journal of Neurophysiology, 93, 3390-3400.

Devlin, B., Cook, E. H., Jr., Coon, H., Dawson, G., Grigorenko, E. L., McMahon, W., et al. (2005). Autism and the serotonin transporter: The long and short of it. Molecular Psychiatry, 10, 1110-1116.

Disney, A. A., Aoki, C., \& Hawken, M. J. (2007). Gain modulation by nicotine in macaque v1. Neuron, 56, 701-713.

Dunbar, G., Boeijinga, P. H., Demazieres, A., Cisterni, C., Kuchibhatla, R., Wesnes, K., et al. (2007). Effects of TC-1734 (AZD3480), a selective neuronal nicotinic 
receptor agonist, on cognitive performance and the EEG of young healthy male volunteers. Psychopharmacology (Berl), 191, 919-929.

Duque, D., Ayala, Y. A., \& Malmierca, M. S. (2015). Deviance detection in auditory subcortical structures: What can we learn from neurochemistry and neural connectivity? Cell and Tissue Research, 361, 215-232.

Duque, D., Malmierca, M. S., \& Caspary, D. M. (2014). Modulation of stimulus-specific adaptation by GABA(A) receptor activation or blockade in the medial geniculate body of the anaesthetized rat. The Journal of Physiology, 592, $729-743$

Edeline, J. M. (2012). Beyond traditional approaches to understanding the functional role of neuromodulators in sensory cortices. Frontiers in Behavioral Neuroscience, 6, 45

Escera, C., \& Malmierca, M. S. (2014). The auditory novelty system: An attempt to integrate human and animal research. Psychophysiology, 51, 111-123.

Faingold, C. L., Boersma Anderson, C. A., \& Caspary, D. M. (1991). Involvement of GABA in acoustically-evoked inhibition in inferior colliculus neurons. Hearing Research, 52, 201-216.

Farley, B. J., Quirk, M. C., Doherty, J. J., \& Christian, E. P. (2010). Stimulus-specific adaptation in auditory cortex is an NMDA-independent process distinct from the sensory novelty encoded by the mismatch negativity. The Journal of Neuroscience, 30, 16475-16484.

Farley, G. R., Morley, B. J., Javel, E., \& Gorga, M. P. (1983). Single-unit responses to cholinergic agents in the rat inferior colliculus. Hearing Research, 11, 73-91.

Featherstone, R. E., Shin, R., Kogan, J. H., Liang, Y., Matsumoto, M., \& Siegel, S. J. (2014). Mice with subtle reduction of NMDA NR1 receptor subunit expression have a selective decrease in mismatch negativity: Implications for schizophrenia prodromal population. Neurobiology of Disease, 73C, 289-295.

Fisher, D. J., Grant, B., Smith, D. M., Borracci, G., Labelle, A., \& Knott, V. J. (2012) Nicotine and the hallucinating brain: Effects on mismatch negativity (MMN) in schizophrenia. Psychiatry Research, 196, 181-187.

Froemke, R. C. (2015). Plasticity of cortical excitatory-inhibitory balance. Annual Review of Neuroscience.

Froemke, R. C., Carcea, I., Barker, A. J., Yuan, K., Seybold, B. A., Martins, A. R., et al. (2013). Long-term modification of cortical synapses improves sensory perception. Nature Neuroscience, 16, 79-88.

Froemke, R. C., Merzenich, M. M., \& Schreiner, C. E. (2007). A synaptic memory trace for cortical receptive field plasticity. Nature, 450, 425-429.

Fujita, I., \& Konishi, M. (1991). The role of GABAergic inhibition in processing of interaural time difference in the owl's auditory system. The Journal of Neuroscience, 11, 722-739.

Gil, Z., Connors, B. W., \& Amitai, Y. (1997). Differential regulation of neocortical synapses by neuromodulators and activity. Neuron, 19, 679-686.

Giocomo, L. M., \& Hasselmo, M. E. (2007). Neuromodulation by glutamate and acetylcholine can change circuit dynamics by regulating the relative influence of afferent input and excitatory feedback. Molecular Neurobiology, 36, $184-200$

Gittelman, J. X., Perkel, D. J., \& Portfors, C. V. (2013). Dopamine modulates auditory responses in the inferior colliculus in a heterogeneous manner. Journal of the Association for Research in Otolaryngology, 14, 719-729.

Gonzalez-Hernandez, T., Mantolan-Sarmiento, B., Gonzalez-Gonzalez, B., \& Perez-Gonzalez, H. (1996). Sources of GABAergic input to the inferior colliculus of the rat. Journal of Comparative Neurology, 372, 309-326.

Habbicht, H., \& Vater, M. (1996). A microiontophoretic study of acetylcholine effects in the inferior colliculus of horseshoe bats: Implications for a modulatory role. Brain Research, 724, 169-179.

Harms, L., Fulham, W. R., Todd, J., Budd, T. W., Hunter, M., Meehan, C., et al. (2014) Mismatch negativity (MMN) in freely-moving rats with several experimental controls. PLoS One, 9, e110892.

Hasselmo, M. E., \& McGaughy, J. (2004). High acetylcholine levels set circuit dynamics for attention and encoding and low acetylcholine levels set dynamics for consolidation. Progress in Brain Research, 145, 207-231.

Hernández, O., Espinosa, N., Pérez-González, D., \& Malmierca, M. S. (2005). The inferior colliculus of the rat: A quantitative analysis of monaural frequency response areas. Neuroscience, 132, 203-217.

Hong, L. E., Moran, L. V., Du, X., O’Donnell, P., \& Summerfelt, A. (2012). Mismatch negativity and low frequency oscillations in schizophrenia families. Clinical Neurophysiology, 123, 1980-1988.

Hormigo, S., Horta Junior Jde, A., Gomez-Nieto, R., \& Lopez, D. E. (2012). The selective neurotoxin DSP-4 impairs the noradrenergic projections from the locus coeruleus to the inferior colliculus in rats. Frontiers in Neural Circuits, 6, 41

Hsieh, C. Y., Cruikshank, S. J., \& Metherate, R. (2000). Differential modulation of auditory thalamocortical and intracortical synaptic transmission by cholinergic agonist. Brain Research, 880, 51-64.

Hurley, L. M., \& Sullivan, M. R. (2012). From behavioral context to receptors: Serotonergic modulatory pathways in the IC. Frontiers in Neural Circuits, 6, 58.

Isaacson, J. S., \& Scanziani, M. (2011). How inhibition shapes cortical activity. Neuron, 72, 231-243.

Ito, T., \& Oliver, D. L. (2010). Origins of glutamatergic terminals in the inferior colliculus identified by retrograde transport and expression of VGLUT1 and VGLUT2 genes. Frontiers in Neuroanatomy, 4, 135.

Ito, T., \& Oliver, D. L. (2012). The basic circuit of the IC: Tectothalamic neurons with different patterns of synaptic organization send different messages to the thalamus. Frontiers in Neural Circuits, 6, 48.

Javitt, D. C., Steinschneider, M., Schroeder, C. E., \& Arezzo, J. C. (1996). Role of cortical $\mathrm{N}$-methyl-D-aspartate receptors in auditory sensory memory and mismatch negativity generation: Implications for schizophrenia. Proceedings of the National Academy of Sciences, 93, 11962-11967.

Jung, F., Stephan, K. E., Backes, H., Moran, R., Gramer, M., Kumagai, T., et al. (2013). Mismatch responses in the awake rat: Evidence from epidural recordings of auditory cortical fields. PLoS One, 8, e63203.

Katzner, S., Busse, L., \& Carandini, M. (2011). GABAA inhibition controls response gain in visual cortex. The Journal of Neuroscience, 31, 5931-5941.

Kelly, J. B., \& Caspary, D. M. (2005). Pharmacology of the inferior colliculus. In J. A Winer, \& C. E. Schreiner (Eds.), The inferior colliculus (pp. 248-281). New York: Springer.

Kimura, F. (2000). Cholinergic modulation of cortical function: A hypothetical role in shifting the dynamics in cortical network. Neuroscience Research, 38, 19-26.

Klepper, A., \& Herbert, H. (1991). Distribution and origin of noradrenergic and serotonergic fibers in the cochlear nucleus and inferior colliculus of the rat. Brain Research, 557, 190-201.

Klinkenberg, I., Blokland, A., Riedel, W. J., \& Sambeth, A. (2013). Cholinergic modulation of auditory processing, sensory gating and novelty detection in human participants. Psychopharmacology (Berl), 225, 903-921.

Knott, V., Impey, D., Philippe, T., Smith, D., Choueiry, J., de la Salle, S., et al. (2014) Modulation of auditory deviance detection by acute nicotine is baseline and deviant dependent in healthy nonsmokers: A mismatch negativity study. Human Psychopharmacology, 29, 446-458.

Knott, V., McIntosh, J., Millar, A., Fisher, D., Villeneuve, C., Ilivitsky, V., et al. (2006). Nicotine and smoker status moderate brain electric and mood activation induced by ketamine, an $N$-methyl-D-aspartate (NMDA) receptor antagonist. Pharmacology Biochemistry and Behavior, 85, 228-242.

Kompus, K., Westerhausen, R., Craven, A. R., Kreegipuu, K., Poldver, N., Passow, S. et al. (2015). Resting-state glutamatergic neurotransmission is related to the peak latency of the auditory mismatch negativity (MMN) for duration deviants: An H-MRS-EEG study. Psychophysiology.

Korostenskaja, M., Nikulin, V. V., Kicic, D., Nikulina, A. V., \& Kahkonen, S. (2007) Effects of NMDA receptor antagonist memantine on mismatch negativity. Brain Research Bulletin, 72, 275-283.

Kujala, T., Aho, E., Lepisto, T., Jansson-Verkasalo, E., Nieminen-von Wendt, T., von Wendt, L., et al. (2007). Atypical pattern of discriminating sound features in adults with Asperger syndrome as reflected by the mismatch negativity. Biological Psychology, 75, 109-114.

Kulesza, R. J., Spirou, G. A., Jr., \& Berrebi, A. S. (2003). Physiological response properties of neurons in the superior paraolivary nucleus of the rat. Journal of Neurophysiology, 89, 2299-2312.

Le Beau, F. E., Rees, A., \& Malmierca, M. S. (1996). Contribution of GABA- and glycine-mediated inhibition to the monaural temporal response properties of neurons in the inferior colliculus. Journal of Neurophysiology, 75, 902-919.

Leach, N. D., Nodal, F. R., Cordery, P. M., King, A. J., \& Bajo, V. M. (2013). Cortical cholinergic input is required for normal auditory perception and experience-dependent plasticity in adult ferrets. The Journal of Neuroscience, 33, 6659-6671.

LeBeau, F. E., Malmierca, M. S., \& Rees, A. (2001). Iontophoresis in vivo demonstrates a key role for GABA(A) and glycinergic inhibition in shaping frequency response areas in the inferior colliculus of guinea pig. The Journal of Neuroscience, 21, 7303-7312.

Lepisto, T., Kajander, M., Vanhala, R., Alku, P., Huotilainen, M., Naatanen, R., et al. (2008). The perception of invariant speech features in children with autism. Biological Psychology, 77, 25-31.

Li, L., \& Kelly, J. B. (1992). Inhibitory influence of the dorsal nucleus of the lateral lemniscus on binaural responses in the rat's inferior colliculus. The Journal of Neuroscience, 12, 4530-4539.

Ma, C. L., Kelly, J. B., \& Wu, S. H. (2002). AMPA and NMDA receptors mediate synaptic excitation in the rat's inferior colliculus. Hearing Research, 168, 25-34.

Malmierca, M. S. (2004). The inferior colliculus: A center for convergence of ascending and descending auditory information. Neuroembryology and Aging, 3 215-229.

Malmierca, M. S. (2015). Auditory system. In G. Paxinos (Ed.), The rat nervous system. Amsterdam: Academic Press.

Malmierca, M. S., Cristaudo, S., Perez-Gonzalez, D., \& Covey, E. (2009). Stimulus-specific adaptation in the inferior colliculus of the anesthetized rat. The Journal of Neuroscience, 29, 5483-5493.

Malmierca, M. S., Hernández, O., Falconi, A., Lopez-Poveda, E. A., Merchán, M., \& Rees, A. (2003). The commissure of the inferior colliculus shapes frequency response areas in rat: An in vivo study using reversible blockade with microinjection of kynurenic acid. Experimental Brain Research, 153, 522-529.

Malmierca, M. S., Hernández, O., \& Rees, A. (2005). Intercollicular commissural projections modulate neuronal responses in the inferior colliculus. European Journal of Neuroscience, 21, 2701-2710.

Malmierca, M. S., Sanchez-Vives, M. V., Escera, C., \& Bendixen, A. (2014). Neurona adaptation, novelty detection and regularity encoding in audition. Frontiers in Systems Neuroscience, 8, 111.

Mathalon, D. H., Ahn, K. H., Perry, E. B., Jr., Cho, H. S., Roach, B. J., Blais, R. K., et al. (2014). Effects of nicotine on the neurophysiological and behavioral effects of ketamine in humans. Frontiers in Psychiatry, 5, 3.

Matsuno, H., Ohi, K., Hashimoto, R., Yamamori, H., Yasuda, Y., Fujimoto, M., et al. (2015). A naturally occurring null variant of the NMDA type glutamate receptor NR3B subunit is a risk factor of schizophrenia. PLoS One, 10, e0116319.

McAlpine, D., \& Palmer, A. R. (2002). Blocking GABAergic inhibition increases sensitivity to sound motion cues in the inferior colliculus. The Journal of Neuroscience, 22, 1443-1453. 
Merchán, M., Aguilar, L. A., Lopez-Poveda, E. A., \& Malmierca, M. S. (2005). The inferior colliculus of the rat: Quantitative immunocytochemical study of GABA and glycine. Neuroscience, 136, 907-925.

Metherate, R., \& Hsieh, C. Y. (2003). Regulation of glutamate synapses by nicotinic acetylcholine receptors in auditory cortex. Neurobiology of Learning and Memory, 80, 285-290.

Metherate, R., \& Weinberger, N. M. (1989). Acetylcholine produces stimulus-specific receptive field alterations in cat auditory cortex. Brain Research, 480, 372-377.

Michie, P. T. (2001). What has MMN revealed about the auditory system in schizophrenia. International Journal of Psychophysiology, 42, 177-194.

Moran, R. J., Campo, P., Symmonds, M., Stephan, K. E., Dolan, R. J., \& Friston, K. J. (2013). Free energy, precision and learning: The role of cholinergic neuromodulation. The Journal of Neuroscience, 33, 8227-8236.

Morley, B. J., \& Kemp, G. E. (1981). Characterization of a putative nicotinic acetylcholine receptor in mammalian brain. Brain Research, 228, 81-104.

Näätänen, R. (1992). Attention and brain function. Hillsdale, NJ: Erlbaum.

Näätänen, R., \& Michie, P. T. (1979). Early selective-attention effects on the evoked potential: A critical review and reinterpretation. Biological Psychology, 8, 81-136.

Näätänen, R., Paavilainen, P., Rinne, T., \& Alho, K. (2007). The mismatch negativity (MMN) in basic research of central auditory processing: A review. Clinical Neurophysiology, 118, 2544-2590.

Nagai, T., Tada, M., Kirihara, K., Yahata, N., Hashimoto, R., Araki, T., et al. (2013). Auditory mismatch negativity and P3a in response to duration and frequency changes in the early stages of psychosis. Schizophrenia Research, 150, 547-554

O'Connor, K. (2012). Auditory processing in autism spectrum disorder: A review. Neurosci. Biobehav. Rev., 36, 836-854

Obara, N., Kamiya, H., \& Fukuda, S. (2014). Serotonergic modulation of inhibitory synaptic transmission in mouse inferior colliculus. Biomedical Research, 35, 81-84.

Olazabal, U. E., \& Moore, J. K. (1989). Nigrotectal projection to the inferior colliculus: Horseradish peroxidase transport and tyrosine hydroxylase immunohistochemical studies in rats, cats, and bats. Journal of Comparative Neurology, 282, 98-118.

Oliver, D. L. (1984). Dorsal cochlear nucleus projections to the inferior colliculus in the cat: A light and electron microscopic study. Journal of Comparative Neurology, 224, 155-172

Palombi, P. S., \& Caspary, D. M. (1996). GABA inputs control discharge rate primarily within frequency receptive fields of inferior colliculus neurons. Journal of Neurophysiology, 75, 2211-2219.

Pang, E. W., \& Fowler, B. (1999). Dissociation of the mismatch negativity and processing negativity attentional waveforms with nitrous oxide. Psychophysiology, 36, 552-558.

Passetti, F., Dalley, J. W., O'Connell, M. T., Everitt, B. J., \& Robbins, T. W. (2000). Increased acetylcholine release in the rat medial prefrontal cortex during performance of a visual attentional task. European Journal of Neuroscience, 12, 3051-3058

Pérez-González, D., Hernandez, O., Covey, E., \& Malmierca, M. S. (2012). GABA(A)-mediated inhibition modulates stimulus-specific adaptation in the inferior colliculus. PLoS One, 7, e34297.

Pérez-González, D., \& Malmierca, M. S. (2012). Variability of the time course of stimulus-specific adaptation in the inferior colliculus. Frontiers in Neural Circuits, 6, 107

Pérez-González, D., \& Malmierca, M. S. (2014). Adaptation in the auditory system: An overview. Frontiers in Integrative Neuroscience, 8,19

Perkins, M. N., \& Stone, T. W. (1983). In vivo release of [3H]-purines by quinolinic acid and related compounds. British Journal of Pharmacology, 80, 263-267.

Ramsey, L. C., Sinha, S. R., \& Hurley, L. M. (2010). 5-HT1A and 5-HT1B receptors differentially modulate rate and timing of auditory responses in the mouse inferior colliculus. European Journal of Neuroscience, 32, 368-379.

Riquelme, R., Saldaña, E., Osen, K. K., Ottersen, O. P., \& Merchán, M. A. (2001). Colocalization of GABA and glycine in the ventral nucleus of the lateral lemniscus in rat: An in situ hybridization and semiquantitative immunocytochemical study. Journal of Comparative Neurology, 432, 409-424.

Saint Marie, R. L., \& Baker, R. A. (1990). Neurotransmitter-specific uptake and retrograde transport of [3H]glycine from the inferior colliculus by ipsilateral projections of the superior olivary complex and nuclei of the lateral lemniscus Brain Research, 524, 244-253.

Saldaña, E., \& Merchán, M. A. (1992). Intrinsic and commissural connections of the rat inferior colliculus. Journal of Comparative Neurology, 319 417-437.

Schmidt, A., Diaconescu, A. O., Kometer, M., Friston, K. J., Stephan, K. E., \& Vollenweider, F. X. (2013). Modeling ketamine effects on synaptic plasticity during the mismatch negativity. Cerebral Cortex, 23, 2394-2406.

Schofield, B. R. (2010). Projections from auditory cortex to midbrain cholinergic neurons that project to the inferior colliculus. Neuroscience, 166, 231-240.

Schofield, B. R., \& Motts, S. D. (2009). Projections from auditory cortex to cholinergic cells in the midbrain tegmentum of guinea pigs. Brain Research Bulletin, 80, 163-170.

Sivaramakrishnan, S., Sterbing-D’Angelo, S. J., Filipovic, B., D’Angelo, W. R., Oliver, D. L., \& Kuwada, S. (2004). GABA(A) synapses shape neuronal responses to sound intensity in the inferior colliculus. The Journal of Neuroscience, 24, 5031-5043.

Thiele, A. (2013). Muscarinic signaling in the brain. Annual review of Neuroscience, 36, 271-294.

Thompson, A. M., \& Thompson, G. C. (2009). Serotonin-immunoreactive neurons in the postnatal MAO-A KO mouse lateral superior olive project to the inferior colliculus. Neuroscience Letters, 460, 47-51.

Tikhonravov, D., Neuvonen, T., Pertovaara, A., Savioja, K., Ruusuvirta, T., Naatanen, R., et al. (2010). Dose-related effects of memantine on a mismatch negativity-like response in anesthetized rats. Neuroscience, 167 , 1175-1182

Tikhonravov, D., Neuvonen, T., Pertovaara, A., Savioja, K., Ruusuvirta, T., Näätänen, R., et al. (2008). Effects of an NMDA-receptor antagonist MK-801 on an MMN-like response recorded in anesthetized rats. Brain Research, 1203, 97-102.

Todd, J., Michie, P. T., Schall, U., Karayanidis, F., Yabe, H., \& Naatanen, R. (2008). Deviant matters: Duration, frequency, and intensity deviants reveal different patterns of mismatch negativity reduction in early and late schizophrenia. Biological Psychiatry, 63, 58-64.

Ulanovsky, N., Las, L., \& Nelken, I. (2003). Processing of low-probability sounds by cortical neurons. Nature Neuroscience, 6, 391-398.

Umbricht, D., Schmid, L., Koller, R., Vollenweider, F. X., Hell, D., \& Javitt, D. C. (2000). Ketamine-induced deficits in auditory and visual context-dependent processing in healthy volunteers: Implications for models of cognitive deficits in schizophrenia. Archives of General Psychiatry, 57, 1139-1147.

Vater, M., Covey, E., \& Casseday, J. H. (1997). The columnar region of the ventral nucleus of the lateral lemniscus in the big brown bat (Eptesicus fuscus): Synaptic arrangements and structural correlates of feedforward inhibitory function. Cell and Tissue Research, 289, 223-233.

Vater, M., Habbicht, H., Kossl, M., \& Grothe, B. (1992). The functional role of GABA and glycine in monaural and binaural processing in the inferior colliculus of horseshoe bats. Journal of Comparative Physiology A, 171, 541-553.

Wacongne, C., Changeux, J. P., \& Dehaene, S. (2012). A neuronal model of predictive coding accounting for the mismatch negativity. Journal of Neuroscience, 32 , 3665-3678.

Warrier, V., Baron-Cohen, S., \& Chakrabarti, B. (2013). Genetic variation in GABRB3 is associated with Asperger syndrome and multiple endophenotypes relevant to autism. Molecular Autism, 4, 48

Watanabe, T., \& Simada, Z. (1971). Picrotoxin: Effect on collicular auditory neurons Brain Research, 28, 582-585.

Windhorst, U., Johansson, H. K., \& Lalley, P. (1999). Microiontophoresis and pressure ejection, modern techniques in neuroscience research. Berlin, Heidelberg. Springer.

Yang, L., Pollak, G. D., \& Resler, C. (1992). GABAergic circuits sharpen tuning curves and modify response properties in the mustache bat inferior colliculus. Journal of Neurophysiology, 68, 1760-1774.

Zhang, D. X., Li, L., Kelly, J. B., \& Wu, S. H. (1998). GABAergic projections from the lateral lemniscus to the inferior colliculus of the rat. Hearing Research, 117, $1-12$. 